\title{
THE VALUE OF TRANSMISSION IN ELECTRICITY MARKETS: EVIDENCE FROM A NUCLEAR POWER PLANT CLOSURE
}

\author{
Lucas Davis \\ Catherine Hausman \\ Working Paper 20186 \\ http://www.nber.org/papers/w20186
NATIONAL BUREAU OF ECONOMIC RESEARCH
1050 Massachusetts Avenue
Cambridge, MA 02138

May 2014

We thank Matt Barmack, Severin Borenstein, Catherine Elder, Jeremiah Johnson, Ryan Kellogg, Shaun McRae, Nolan Miller, and seminar participants at the MIT CEEPR Workshop, the University of California Energy Institute, the University of Illinois, and the University of Michigan for valuable comments. We thank Mackenzie Humble for assistance assembling the price data from CAISO. We have not received any financial compensation for this project nor do we have any financial relationships that relate to this research. The views expressed herein are those of the authors and do not necessarily reflect the views of the National Bureau of Economic Research.

NBER working papers are circulated for discussion and comment purposes. They have not been peerreviewed or been subject to the review by the NBER Board of Directors that accompanies official NBER publications.

(C) 2014 by Lucas Davis and Catherine Hausman. All rights reserved. Short sections of text, not to exceed two paragraphs, may be quoted without explicit permission provided that full credit, including (C) notice, is given to the source. 
The Value of Transmission in Electricity Markets: Evidence from a Nuclear Power Plant Closure Lucas Davis and Catherine Hausman

NBER Working Paper No. 20186

May 2014

JEL No. L51,L94,Q41,Q54

\begin{abstract}
$\underline{\text { ABSTRACT }}$
Reliable estimates of the value of electricity transmission are critical if these heavily-regulated investments are to be made cost-effectively. In this paper, we exploit the abrupt closure of the San Onofre Nuclear Generating Station (SONGS) in February 2012. During the previous decade, SONGS had produced about $8 \%$ of the electricity generated in California, so its closure had a pronounced impact on the wholesale market, requiring large and immediate increases in generation from other sources. We find that in the months following the closure, almost all of the lost generation from SONGS was met by natural gas plants inside California at an average cost of almost $\$ 68,000$ per hour. During high demand hours, we find that as much as $75 \%$ of the lost generation was met by plants located in the southern part of the state. Although lower-cost production was available elsewhere, transmission constraints and other physical limitations of the grid severely limited the ability of other producers to sell into the southern California market. These constraints also made it potentially more profitable for certain plants to exercise market power, and we find evidence consistent with one company acting noncompetitively. Overall, the constraints increased generation costs by an average of $\$ 4,500$ per hour, implying that the value of additional transmission capacity is about $\$ 380$ million.
\end{abstract}

\author{
Lucas Davis \\ Haas School of Business \\ University of California \\ Berkeley, CA 94720-1900 \\ and NBER \\ ldavis@haas.berkeley.edu \\ Catherine Hausman \\ Weill Hall \\ 735 S. State St. \#4215 \\ Ann Arbor, MI 48109-3091 \\ chausman@umich.edu
}

An online appendix is available at:

http://www.nber.org/data-appendix/w20186 


\section{Introduction}

Geographic integration of markets improves the allocation of production across firms, reduces price dispersion, and increases consumer and producer surplus. These benefits are particularly important in electricity markets because unlike most other goods, electricity cannot be cost-effectively stored. Supply must meet demand at all times, or the frequency in the grid will fall outside of a narrow tolerance band, causing blackouts. In addition, electricity demand is highly variable and highly inelastic. As a result, the market clears mostly on the supply side, with production ramping up and down to meet demand. Geographic integration helps smooth this volatility, reducing the frequency and severity of price spikes and better allocating production across plants.

Connecting electricity markets requires substantial investments in transmission lines and other infrastructure. In the United States, total investments in electricity transmission reach almost $\$ 15$ billion annually (Edison Electric Institute, 2014). This spending is expected to increase over the next several years as additional transmission capacity is needed to help integrate wind, solar, and other intermittent generation technologies. These are large, longlived projects, so making the right level of investment in the right locations is extremely important. Reliable estimates of the value of transmission are critical if these investments are to made cost-effectively.

Quantifying the value of transmission is challenging. Investments in transmission capacity are endogenous responses to changes in market conditions, making it hard to construct a credible counterfactual for what would have happened without these investments. In addition, investments are anticipated years in advance, so before-and-after comparisons can be difficult to interpret. Moreover, the engineering models that are used in the industry rely on strong simplifying assumptions that are difficult to verify empirically.

In this paper, we use evidence from a nuclear power plant closure to quantify the value of transmission in the California electricity market. Between 2005 and 2011, the San Onofre Nuclear Generating Station (SONGS) generated an average of 16 million megawatt hours of electricity annually, making it one of the largest electric generating facilities in California. During this period, SONGS generated enough electricity to meet the needs of 2.3 million California households ${ }^{1}-$ about $8 \%$ of all electricity generated in the state. Moreover, SONGS was even more valuable than these numbers suggest because of its location between Los Angeles and San Diego, two enormous demand centers. Although there is transmission that

\footnotetext{
${ }^{1}$ U.S. DOE/EIA "Electric Sales, Revenue, and Average Price," November 2013, Tables T1 and T2. California households used an average of 6.9 megawatt hours in 2012.
} 
connects Southern California to the rest of the state, the capacity is limited, implying that a large part of demand must be met locally. SONGS was closed abruptly and permanently in February 2012, when workers discovered problems with the plant's steam generators. Because of the plant's size and prominence, the closure provides a valuable natural experiment for learning about the value of electricity transmission capacity.

Even in a world without transmission constraints or market power, closing a large generation source will impact the price of wholesale electricity. Like other nuclear power plants, SONGS produced electricity at very low marginal cost. Consequently, the plant was always near the top of the "merit-order," operating around the clock and providing a consistent source of electricity. When SONGS was closed, this generation had to be made up for by operating other, more expensive generating resources. We use rich micro-data from a variety of sources and an econometric model to identify those marginal resources that would be expected to increase production. Overall, we find that bringing these additional power plants online cost around $\$ 63,000$ each hour.

In addition to these merit-order effects, the closure caused transmission constraints to bind, essentially segmenting the California market. Prior to the closure, transmission capacity between Northern and Southern California was usually sufficient, so that wholesale prices equalized in the two regions during the vast majority of hours. Although SONGS was occasionally shut down temporarily for refueling or maintenance, plant managers were careful to schedule these outages during the winter, when demand is low. Beginning with the permanent closure in 2012, we document a substantial divergence in prices between Northern and Southern California.

This binding transmission constraint and other physical constraints of the grid meant that it was not possible to meet all of the lost output from SONGS using the lowest cost available generating resources. We find that during low demand hours, the change in generation follows closely the merit order, with about half of the increased generation coming from Southern California and the other half coming from Northern California. During high demand hours, however, we find significant "out-of-merit" effects: higher cost generating units coming online more than we would have expected. In high demand hours in 2012, we find that as much as $75 \%$ of the lost generation was met by plants located in Southern California. On average, these constraints increased generation costs by an average of $\$ 4,500$ per hour, implying that the total cost of additional natural gas generation was almost $\$ 68,000$ per hour.

Distinguishing between merit-order and out-of-merit effects is challenging because one must construct a credible counterfactual for what the pattern of generation would have been with- 
out transmission constraints. The empirical strategy that we adopt in the paper is to exploit the fact that prior to the closure, transmission constraints were rarely binding in the California market. We use data from this pre-period to describe flexibly the relationship between unit-level generation and system-wide demand. These estimates are used to predict what operating behavior would have been after the SONGS closure were there no transmission constraints. We then compare generating units' actual behavior with this counterfactual to measure out-of-merit effects. This approach affords several advantages over a simple before and after comparison. Most importantly, we are able to account for concurrent changes to hydroelectric resources, renewables, demand, and other market conditions - all of which would confound a before and after comparison.

Our results provide a detailed account of economic and environmental outcomes. We find that the SONGS closure increased the cost of electricity generation in California by about $\$ 350$ million during the first twelve months. This is a large change, equivalent to a 13 percent increase in total in-state generation costs, yet it went almost completely unnoticed because of a large offsetting decrease in natural gas prices that occurred in 2012. In fact, a simple beforeand-after calculation would have erroneously concluded that the SONGS closure actually decreased electricity prices. The SONGS closure also had important implications for the environment, increasing carbon dioxide emissions by 9 million tons in the twelve months following the closure. To put this in some perspective, this is the equivalent of putting 2 million additional cars on the road, and implies a social cost of emissions of almost $\$ 320$ million per year. ${ }^{2}$

Of this $\$ 350$ million in increased private generation costs during the first twelve months, we attribute $\$ 40$ million to transmission constraints and other physical limitations of the grid. Over a ten-year time horizon with a $1 \%$ discount rate, this implies that the value of additional transmission capacity is $\$ 380$ million. As we discuss, this is substantially higher than the cost of infrastructure projects that would relieve some of the constraints. The California Independent System Operator evidently agrees, and since 2013 has been increasing transmission capacity and making other investments aimed at better integrating northern San Diego county with the rest of the California market.

We are also able to determine which individual plants changed their behavior the most after the SONGS closure. Because of the transmission constraints, the largest out-of-merit increases are at Southern plants, and the largest out-of-merit decreases are at Northern

\footnotetext{
${ }^{2}$ According to U.S. DOE/EIA Annual Energy Review, September 2012, Table 2.8 "Motor Vehicle Mileage, Fuel Consumption, and Fuel Economy", light-duty vehicles with a short wheelbase use an average of 453 gallons of gasoline annually. For each gallon of gasoline, 19.6 pounds of carbon dioxide are emitted.
} 
plants. Surprisingly, we also find large out-of-merit decreases during high demand hours at two Southern plants: Alamitos and Redondo, both owned by the same company. This was unexpected but, as it turns out, not coincidental. The Federal Energy Regulatory Commission recently alleged market manipulation at these plants over the period 2010 to 2012, for which JP Morgan paid fines of over $\$ 400$ million. The fact that the results clearly identified these two plants suggests that our approach may serve as a useful diagnostic tool. Although a large out-of-merit effect does not prove that a plant is exercising market power, it is a good indicator of unusual behavior.

Our paper contributes to a small but growing literature on the value of geographic integration in electricity markets (Mansur and White, 2012; Wolak, 2012; Ryan, 2013; Birge et al., 2013). Previous studies of transmission constraints in electricity markets have either used stylized theoretical models (Cardell, Hitt and Hogan, 1997; Joskow and Tirole, 2000), or Cournot simulations (Borenstein, Bushnell and Stoft, 2000; Ryan, 2013). Our methodology is novel, as it decomposes changes in quantity into merit-order and out-of-merit effects without requiring strong assumptions about the firms' objective function or an explicit representation of the physical constraints of the electric grid. We see broad potential for applying this approach elswhere. Whereas most economic studies of wholesale electricity markets have relied on confidential data from the system operator and other sources, our analysis relies entirely on publicly-available data. Consequently, it would be relatively straightforward to perform similar analyses in other electricity markets, both for quantifying the impacts of large changes in generation and transmission infrastructure, and for diagnosing unusual changes in firm behavior.

\section{Background}

\section{$2.1 \quad$ Electricity Markets}

In the United States, electricity generation in 2012 came from coal (37\%); natural gas (30\%); nuclear (19\%); hydro (7\%); and wind, solar and other renewables (5\%). ${ }^{3}$ This mix of technologies reflects cost, flexibility, and environmental objectives. Wind, solar, and other renewables have near zero marginal cost, so they occupy the top of the merit order. Next in the order is nuclear, which has a low marginal cost relative to fossil fuel plants. Fossil fuel plants follow, with coal tending to be cheaper than natural gas. Depending on fuel prices,

\footnotetext{
${ }^{3}$ Table 7.2a "Electricity Net Generation: Total (All Sectors)" in EIA (2013A).
} 
however, there may be some highly-efficient natural gas plants with lower marginal cost than particularly inefficient coal plants.

Regulation of electricity markets varies across states and has changed over time. Under the classic regulatory model still used in many states today, electric utilities receive exclusive rights to provide electricity within given geographic areas and charge rates set by cost-ofservice regulation. These vertically-integrated utilities typically perform all the activities required to supply electricity: generating electricity, operating the transmission and distribution networks, and providing retail services.

In part as a response to the limitations of cost-of-service regulation, several states began to deregulate their electricity markets beginning in the late 1990s. In most states, the deregulation process separated generation from transmission and distribution. Whereas most economists believe generation is potentially competitive, transmission and distribution are natural monopolies. Wholesale electricity markets were established in several different regions, and regulators required utilities to sell all or part of their existing electric generating portfolios to independent power producers.

Deregulation has resulted in gains in operating efficiency (Fabrizio, Rose and Wolfram, 2007; Davis and Wolfram, 2012), but it has also introduced opportunities for generation companies to exercise market power (Borenstein and Bushnell, 1999; Borenstein, Bushnell and Wolak, 2002; Bushnell, Mansur and Saravia, 2008; Hortacsu and Puller, 2008). As with any market, the scope for individual firms to affect prices depends on the size of the market and the number of firms. With electricity, however, the lack of cost-effective storage and inelastic short-run demand makes the market particularly susceptible to market power, even when market concentration is relatively low.

Economists have also long recognized the key role of transmission capacity in deregulated electricity markets (Cardell, Hitt and Hogan, 1997; Bushnell, 1999; Borenstein, Bushnell and Stoft, 2000; Joskow and Tirole, 2000; Wolak, 2012; Ryan, 2013). When transmission lines are unconstrained, electricity moves between markets at virtually no cost, prices are equated across markets, and the effective size of the market is large. However, when transmission capacity is limited, the effective size of the local market shrinks, potentially making it more profitable for producers to withold generation. There is also related work on how centralized markets can increase the effective size of the market. Mansur and White (2012) document how the expansion of a wholesale electricity market from the Eastern United States to the Midwest led to a substantial increase in efficiency, equating prices across regions and improving allocative efficiency. 


\subsection{The California Landscape}

California was part of this initial wave of electricity deregulation. California's wholesale electricity market was launched in April 1998, with all three major investor owned utilities required to buy and sell electricity through this new market. Around the same time, the utilities were required to sell nearly all of their natural gas power plants to independent power producers. By the end of the 1990s, independent power producers controlled more than 30 percent of the electricity generating capacity in the state.

For the first two years wholesale prices varied widely across hours, but average monthly prices stayed below $\$ 50$ per megawatt hour. Then in 2000 the nascent market was put to the test. The year was unusually dry, leading to below average hydro generation, and the summer was unusually hot, increasing demand. Starting in June 2000, wholesale prices spiked and for the next several months average monthly prices exceeded $\$ 100$ per megawatt hour. The prices were devastating to the utilities, who were required to buy electricity in the wholesale market and then sell it to customers at lower, regulated rates. California's largest utility, Pacific Gas and Electric, declared bankruptcy in 2001, and the state eventually intervened and suspended the market.

Most economic analyses of this period have concluded that generation companies exercised market power that pushed prices considerably higher than they would have gone due to market fundamentals (Borenstein, Bushnell and Wolak, 2002; Joskow and Kahn, 2002; Puller, 2007). Borenstein, Bushnell and Wolak (2002), for example, finds that about half of the increase in electricity expenditures during summer 2000 was due to market power. These studies are innovative in the broader industrial organization literature because they illustrate how under tight market conditions firms can exercise unilateral market power even with a small market share. This was noted in the many studies of the crisis, and also presaged by Borenstein and Bushnell (1999) using a Cournot model to simulate the California market.

The California market today looks considerably different. First, a much higher fraction of electricity is sold using long-term contracts. This reduces the incentive for producers to withhold generation in the spot market because they cannot influence the price of the output already committed through contracts (Allaz and Vila, 1993). Second, short-run demand for electricity in California is more elastic than it was in 2000. Although the vast majority of residential and commercial customers continue to face time-invariant retail prices, a growing number of California industrial customers face more dynamic rates. Third, the state's renewable portfolio standard and other state and federal policies have led to substantial in- 
vestments in wind, solar, and other renewables. This has increased total generation capacity during a period in which demand has been relatively flat.

Table 1 describes electricity generation in California by source in 2011. By far the largest source of generation is natural gas, with $44 \%$ of total generation. The second largest source is hydro, accounting for $21 \%$ of generation. The two nuclear plants, San Onofre and Diablo Canyon, each contributed approximately $9 \%$ of total generation in 2011. Finally, geothermal, wind, solar, and other renewables account for about $13 \%$ of total generation. Thus, overall the the California generation portfolio is substantially less carbon intensive than the rest of the United States, with more emphasis on natural gas, hydro, and renewables.

\subsection{The San Onofre Nuclear Generating Station}

San Onofre Nuclear Generation Station (SONGS) is a retired two-reactor, 2,150 megawatt nuclear power plant, operated by Southern California Edison (SCE). ${ }^{4}$ SONGS was valuable to the California market not just because it generated a large amount of generation, but also because of its prime location. Located in the Northwest corner of San Diego County, SONGS provided electricity in the highly-populated corridor between Los Angeles and San Diego, where there are few other large power plants.

Trouble for SONGS started on January 31, 2012 when operators detected a small leak inside one of the steam generators. The reactor with the leak was shut down immediately; the other reactor that had already been shut down three weeks prior for a routine refueling outage. Although it was not known at the time, neither reactor would ever operate again. On investigation, it was discovered that thousands of tubes in the steam generators in both units were showing premature wear. This was followed by months of testing and, eventually, a proposal to the Nuclear Regulatory Commission (NRC) to restart one of the units at reduced power level. An additional eight months passed without a decision from the NRC. Meanwhile, policymakers grew concerned that without SONGS, the grid would face "additional operational challenges in the Los Angeles Basin and San Diego areas" (CEC 2012), relating to the possibility of insufficient summer capacity and the possibility of transmission constraints (NERC 2012; CAISO 2012).

Facing uncertainty about the NRC ruling, and continued costs of maintaining SONGS in a state of readiness, SCE made the decision in June 2013 to permanently retire the facility. "SONGS has served this region for over 40 years," explained Ted Craver, Chairman and

\footnotetext{
${ }^{4} \mathrm{SCE}$ is also the majority owner (78\%). The other owners are San Diego Gas \& Electric (20\%) and the city of Riverside $(2 \%)$.
} 
CEO, "but we have concluded that the continuing uncertainty about when or if SONGS might return to service was not good for our customers, our investors, or the need to plan for our region's long-term electricity needs." (Southern California Edison, 2013). ${ }^{5}$

The SONGS closure was abrupt, permanent, and unexpected, making it a valuable natural experiment for learning about behavior in electricity markets. It is worth noting that there is some precedent for studying changes in market behavior during changes in nuclear plant operations. In particular, Wolfram (1999) instruments for wholesale electricity prices using available nuclear capacity, exploiting the large quasi-random changes in electricity supply due to unplanned outages. Our study is different in that we focus on a permanent shock rather than temporary outages, but the identifying variation is similar.

The SONGS closure is particularly interesting for an empirical analysis because whereas most large plant closures are anticipated months or even years in advance, the SONGS closure was abrupt and unexpected. This sharpens the impact and interpretation considerably as it provided little opportunity for the anticipatory investments in generation and transmission that typically accompany infrastructure openings and closings. In addition, SONGS is of particular interest because it operated in a deregulated electricity market. In states where generation companies are regulated using cost-of-service regulation there is less scope (and less incentive) for generating units to exercise market power in response to changes in market conditions.

Finally, the SONGS closure is worth understanding because it evokes parallels with the California electricity crisis. The year 2012 was similar to 2000 in that both years were unusually dry, resulting in low levels of hydro generation. Removing an enormous generation source like SONGS, particularly during a bad year for hydroelectric generation, might have been expected to create tight supply conditions like in 2000. As it turns out, however, market prices and other outcomes in 2012 were very different from the experince in 2000. We think that comparing the behavior of the market in 2012 to 2000 can yield insights, both about firm behavior and market design.

\footnotetext{
${ }^{5}$ SONGS is one of three U.S. nuclear power plants to close over the last decade. Crystal River and Kewaunee were both officially closed in 2013. Additionally, Vermont Yankee is expected to close in 2014. For a recent survey of some of the broader challenges faced by nuclear power see Davis (2012).
} 


\section{Data}

For this analysis we compiled data from a variety of difference sources including the U.S. Department of Energy's Energy Information Administration (EIA), the California Independent System Operator (CAISO), and the U.S. Environmental Protection Agency (EPA). As we mention in the introduction, a strength of our analysis is that it relies entirely on publicly-available data.

\subsection{Generation Data from EIA}

We first assembled a dataset of annual plant-level electricity generation from the EIA's Power Plant Operation Report (EIA-923). This is a required survey for all U.S. electric generating facilities with more than one megawatt of capacity. The advantage of these data is that they are comprehensive, including not only large fossil-fuel generating units, but also smaller and less frequently operated units, as well as hydroelectric facilities, solar and wind plants, and nuclear plants. Most California plants complete the survey only once per year, so we perform all analyses of the EIA-923 data at the annual level, relying on the other datasets listed below for within-year comparisons. These data also contain information on plant characteristics, including operator name, fuel type, and some details about the generation technology. We supplement these characteristics with additional information (county, capacity, and vintage) from another Department of Energy dataset, the Annual Electric Generator Report (EIA$860)$.

Table 2 describes California electricity generation in 2011 and 2012. SONGS was closed in early February 2012, so the columns can be approximately interpreted as before and after the SONGS closure. Panel A reports average monthly generation by fuel type. Nuclear generation decreased by 1.5 million megawatt hours monthly. Interestingly, 2012 was also an unusually bad year for hydroelectric power, with a decrease of 1.3 million megawatt hours monthly. Offsetting these decreases, natural gas generation in California increased by 2.6 million megawatt hours monthly. There is also a modest increase in wind generation, and close to zero changes for all other categories.

Panel B examines natural gas generation more closely. These categories primarily distinguish between whether plants are owned by electric utilities or independent power producers, and whether or not the plants are cogeneration facilities. The two largest categories are "Independent Power Producer Non-Cogen" and "Electric Utility." Both increase substantially in 2012. Generation is essentially flat in all other categories between 2011 and 2012. In some 
cases (e.g. industrial non-cogen) there are large percentage changes but from a small base level. It is difficult to make definitive statements based on these aggregate data, but this is consistent with plants in these other categories being much less able to respond to market conditions. With industrial, commercial, and cogeneration facilities, electrical output is a joint decision with other processes (e.g. oil extraction or refining, steam production, etc.), which limits the ability of these plants to respond quickly to changes in market conditions.

\subsection{Generation Data from CAISO}

To complement the EIA data, we next assembled a database using publicly-available records from CAISO. About 80 percent of the electricity used in California is traded through CAISO. All of California's investor-owned utilities and most municipally-owned electric utilities buy power through CAISO. An important exception is the munipally-owned Los Angeles Department of Water and Power (LADWP), which maintains its own electricity generation and also imports power from other states through long-term contracts.

The data from CAISO describe hourly data on electricity generation by broad categories (thermal, imports, renewables, large hydroelectric, and nuclear). The renewables category is disaggregated into six subcategories (geothermal, biomass, biogas, small hydroelectric, wind, and solar). See CAISO (2013c) for details. Table 2, Panel C describes generation by category in 2011 and 2012. These data corroborate the general pattern observed in the EIA data. From 2011 to 2012, there is a large increase in thermal generation and large decreases in nuclear and hydroelectric generation.

An important advantage of the CAISO data is that they also track imports. Between 2011 and 2012 imports increased from 5.45 to 5.77 million megawatt hours monthly. This is a substantial increase, but offsets less than $1 / 5$ th of the shortfall experienced from the SONGS closure, and only about 1/10th of the combined shortfall from SONGS and the decrease in hydroelectric generation. Both the EIA data and CAISO data suggest that California thermal generation played the primary role in making up for the lost generation from SONGS. We examine the role of imports in greater depth in Section 5.1. 


\subsection{Generation Data from CEMS}

We next built a database of hourly emissions, heat input, and electricity generation by generating unit using the EPA's Continuous Emissions Monitoring System (CEMS). The CEMS data contain these hourly data as well as descriptive information for each generating unit, including owner name, operator name, technology, primary and secondary fuel, and vintage. Finally, we match each generating unit to one of the three price locations using the "Control Area Generating Capability List" from CAISO (2013D).

CEMS data have been widely used in economic studies of generator behavior because they provide a high-frequency measure of generation at the generating unit level. See, e.g., Joskow and Kahn (2002); Puller (2007); Mansur (2007); Holland and Mansur (2008). CEMS data are highly accurate because facilities must comply with specific requirements for maintenance, calibration, and certification of monitoring equipment, and because the methodology used for imputing missing data creates an incentive for generating units to keep monitoring equipment online at all times.

During our sample period, 107 plants in California report to CEMS. ${ }^{6}$ In 2011, these plants represent $30 \%$ of total generation in California and $62 \%$ of total natural gas generation. This relatively low fraction of generation covered by CEMS reflects that a large share of California generation comes from nuclear, hydro, and renewables - none of which are in CEMS. In addition, as discussed above, one third of natural-gas fired generation in California is from cogeneration, industrial, and commercial facilities, which are generally not in CEMS. Indeed, generation reported in CEMS in 2011 is $96 \%$ of non-cogen natural gas-fired generation by electric utilities and independent power producers reported in the EIA data.

Despite the imperfect coverage, the CEMS data are extremely valuable, because they are the only publicly available information on hourly, generating unit-level outcomes. Moreover, by combining the CEMS data with EIA and CAISO data, we are able to get a sense of how much our results might be affected by focusing exclusively on CEMS generating units. Table A1 in the Online Appendix lists the largest plants that do not appear in CEMS. Overall, these plants tend to be quite small, or to be types of facilities (e.g. cogeneration plants, industrial facilities) that are not able to respond quickly to market changes.

While CEMS data describe gross generation, for this analysis we would ideally observe net generation. The difference between the two is equal to "in-house load," which is the electricity the plant uses to run, for instance, cooling equipment or environmental controls. As such,

\footnotetext{
${ }^{6} \mathrm{CEMS}$ reporting requirements do not change during our sample period.
} 
net generation is what is sold on the grid. Reliable plant-level or unit-level estimates of the ratio between net and gross generation are not available. In the analyses that follow we use an implied measure of net generation, which we calculate as $95.7 \%$ of gross generation. This 4.3-percent difference is the median difference in our sample between net generation from EIA and gross generation from CEMS, after dropping some outliers. ${ }^{7}$ Kotchen and Mansur (2013) make a similar comparison using national data, finding a 5-percent mean difference.

\subsection{Wholesale Price Data}

We also obtained hourly wholesale electricity prices from CAISO. We use prices at three locations: NP15 (Northern California), ZP26 (Central California), and SP26 (Southern California). Figure 1 shows the weekly maximum price for the North and South. We focus on maximum prices because transmission constraints are only likely to bind during a few, high demand hours. Maximum prices are generally very similar prior to the SONGS closure, but they diverge substantially in 2012. Figure 2 shows the price difference between Northern and Southern California at 3 p.m. each weekday, a time when transmission constraints are more likely to bind. Again, there is clear evidence of an increase in the post-period price differentials. After the SONGS closure, there are many more days with positive differentials, including a small number of days with differentials that exceed $\$ 40$.

\section{Empirical Strategy and Generation Regressions}

\subsection{Creating a Credible Counterfactual}

Our objective is to determine which power plants increased generation to make up for the 2,150 megawatts of capacity that became unavailable when SONGS closed in February 2012. Although at first glance this might appear to be a relatively straightforward exercise, simple before-and-after comparisons would not be credible. As we showed earlier, hydroelectric generation was low in 2012. This alone necessitated substantial increases in generation from

\footnotetext{
${ }^{7}$ Specifically, we examine generation data for 2005-2011 plants that appear in both CEMS and EIA. We calculate the annual net to gross ratio for each plant, using net generation as reported to EIA and gross generation as reported to CEMS. The median ratio is 0.966 , but there are implausible outliers, such that the average is greater than 1. In particular, if some but not all generating units report to CEMS, this ratio can appear larger than 1. Dropping these outliers, the median is 0.957 and the average is 0.926 .
} 
thermal plants, making it difficult to interpret before-and-after comparisons like our Table 2.

One potential approach for estimating the causal impact of the SONGS closure would have been to use a regression-discontinuity (RD) research design, comparing generation immediately before and after the SONGS closure. This approach has a great deal of intuitive appeal, but is only useful for estimating a very short-run effect, i.e. changes in generation during the days or weeks following the closure. Although this is somewhat interesting, we are much more interested in longer-run changes in generation patterns. In particular, we want to be able to examine June, July and August 2012, when air-conditioning and other factors lead electricity consumption to reach its annual peak. The RD approach is not helpful for examining this peak period because it occurs several months after the closure.

Instead, the approach we adopt in this paper is to construct an econometric model of the relationship between system-wide demand and unit-level generation, and then to use this model to quantify changes in generation post closure. The basic idea is simple. System-wide demand varies substantially hour to hour, as a function of weather and economic activity. Low-cost generating units operate most hours of the year, regardless of system-wide demand, while higher-cost generating units turn on only during relatively high demand hours. The first thing we do is describe this relationship non-parametrically by estimating a series of what we call "generation regressions."

We estimate these regressions using data from before the closure, when transmission constraints were rarely binding in the California market. These regressions are thus an empirical representation of operating behavior in an unconstrained market, and they primarily reflect differences in marginal cost across generating units. During the post-period, however, we expect transmission constraints and other physical limitations of the grid to change the ordering of generating units. In particular, electricity generated by units in the immediate vicinity of SONGS became more valuable, potentially leading these units to be used even at lower levels of system-wide demand.

As we describe in the introduction, we distinguish between two different effects: (1) the "merit-order" change in generation is when the next generating unit along the marginal cost curve is brought online; and (2) the "out-of-merit" change in generation is when higher cost generating units that would normally be offline are brought online because of transmission constraints, voltage support, or other considerations. In this section we describe our approach in detail, highlighting the key assumptions required for each stage in the analysis.

An alternative to our ex-post empirical approach would have been to simulate counterfactuals 
using an engineering model of the electrical grid combined with a structural model of firm optimization. However, our method is better suited to the application we consider for several reasons. First, while Cournot simulations have been used to study two-node transmission problems, the transmission constraints in our application are much more complex. And while engineering models exist that attempt to capture these features (e.g. GE MAPS), they rely on simplifying assumptions that only approximately describe Kirchhof's laws and the engineering properties that govern how electricity moves. In practice, electric grid system operators use a combination of output from such models and real-time information about system conditions.

Performing counterfactual simulations would also require strong assumptions about generator and system operator behavior. While the objective function for independent power producers is relatively clear, describing behavior by investor-owned utilities is more difficult because they are subject to rate-of-return regulation. System operator behavior is important as well. During this period, CAISO was actively implementing new automated bid mitigation procedures and increasing the use of exceptional dispatches (CAISO 2013B). Modeling these rapidly evolving market practices explicitly poses real challenges and would have required not only imposing these constraints in the model but also making strong assumptions about generators' expectations about these practices.

\subsection{Generation Regressions by Category}

The core of our econometric model is a system of what we call "generation regressions," which describe non-parametrically the relationship between system-wide demand and generation at individual sources. We estimate these regressions first for broad categories of generation and then later, in Section 4.3, for individual generating units. For the generation regressions by category the estimating equation takes the following form:

$$
\text { generation }_{i t}=\sum_{b}\left(\gamma_{b i} \cdot \mathbb{1}\left\{\text { system-wide demand }_{t}=b\right\}\right)+\varepsilon_{i t}
$$

The dependent variable is electricity generation for category $i$ in hour $t$, measured in megawatt hours. We use the categories reported in CAISO data: thermal, large hydro, imports, nuclear, and renewables. In addition, we separate thermal into generation that appears in CEMS and generation that does not, where the latter is calculated as the difference between thermal generation reported by CAISO and thermal generation reported by CEMS.

The only independent variables in the regression are a set of indicator variables corresponding 
to different levels of total system demand. We divide system-wide demand into bins of equal width, indexed by $b$. For convenience, we define the bin width as 2,150/2 =1,075 megawatt hours, so that we can assume that system demand increased by two bins following the SONGS closure. We have experimented with alternative bin widths, and the results are similar with both more and fewer bins.

We do not include a constant in the regression, as the indicator variables sum to unity. We could equivalently drop one and interpret the coefficients relative to the excluded bin, but our approach makes it easier to interpret the estimated coefficients. Without including a constant, the coefficients $\gamma_{b i}$ are equal to the average generation for category $i$ when system demand is at level $b$. If there were no dynamic dispatch considerations and no plant outages, this coefficient would be equal to zero up until the point when lower-cost generating units had already been turned on to meet demand, and then would be equal to the unit's capacity. Because there are no additional regressors, this is formally equivalent to calculating conditional means for different ranges of system-wide demand.

We estimate equation (1) using hourly data from 2010 and 2011, the two years leading up to the SONGS closure. We begin the sample on April 20, 2010 because prior to that date, we do not observe CAISO generation data. Additionally, we drop a small number of days (fewer than ten) for which data from CAISO are incomplete. Because the coefficients $\gamma_{b i}$ are allowed to differ by generation category, we estimate six separate regressions, one for each category. Figure 3 plots the estimated coefficients. In all plots, the x-axis is total generation from all sources, divided into bins. The y-axis is average source-specific generation in MWh. We plot all six categories using the same scale for the y-axis, so that one can immediately compare both the level and responsiveness of generation.

The CEMS units (Panel A) are very responsive across all quantiles of demand. Large-scale hydro (Panel B) is only somewhat responsive, which is a bit surprising given the potential for using large hydroelectric facilities to follow demand fluctuations. We thought this might be because 2011 had relatively high water supply, so we also examined the generation regression for 2012. Though the overall level of hydro generation is lower in 2012, the slope is about the same. Imports (Panel C) are also somewhat responsive, but only for relatively low demand hours. Past the median level of demand, imports are essentially flat. Nuclear (Panel D) and renewables (Panel E) are not responsive, as expected - the nuclear unit (Diablo Canyon) is baseload, and renewable generation is exogenously determined by weather.

It is interesting to compare these results with the aggregate pattern of generation in Table 2. Both show, in some sense, the ability of different generation sources to respond to changes in 
demand, albeit on very different time scales. The year-to-year comparison suggests that the majority of the response to the SONGS closure came from natural gas generation, and this is consistent with the hour-to-hour responsiveness observed in Panel A. Similarly, most of the other categories showed relatively little increase in 2012, and this accords with the lack of hour-to-hour responsiveness in Panels B-F. Finally, it is important to note that, while hydroelectric resources display some hour-to-hour variation in Figure 3, the year-to-year variation is entirely exogenous - it depends on total precipitation.

\subsection{Unit-Level Generation Regressions}

The generation regressions by category give a valuable overview, but they provide no detail about which particular plants tend to be the most responsive to system-wide demand, nor about the geographic location of production. Therefore, we next estimate generation regressions for each unit that appears in the CEMS data. The estimating equation for these regressions is very similar to equation (1) except the unit of observation is now the individual generating unit $j$,

$$
\text { generation }_{j t}=\sum_{b}\left(\alpha_{b j} \cdot \mathbb{1}\{\text { net system-wide demand } t=b\}\right)+e_{j t} .
$$

The right-hand side bins are now defined over total generation by all California CEMS units. This is the net or residual demand, after generation from renewables, imports, and non-CEMS units has been subtracted from the total system demand. We use this rather than total system demand because we want to identify the ordering within the category of natural gas units.

We estimate these unit-level generation regressions using two separate samples corresponding to before and after the SONGS closure. Observing plant behavior before the closure allows us to construct a counterfactual for what would have occurred if SONGS had not closed. As we describe in the next section, the behavior of the natural gas units before the closure (the "pre-period") can then be compared to the behavior after the closure (the "post-period"). Returning to equation (2), note that we use net demand because we want to attribute changes from the pre-period to the post-period only to the SONGS outage, and the residual demand will not be confounded by concurrent changes to renewables, hydro, or demand. We elaborate on this below.

For the pre-period, we again use data from April 20, 2010 to January 31, 2012, the year and a half leading up to the SONGS closure. We drop four generating units which are 
owned by the Los Angeles Department of Water and Power (LADWP). As described earlier, LADWP maintains its own electricity generation and also imports power from other states through long-term contracts, and it is not part of the CAISO market. Finally, for the main analysis we exclude generating units that enter or exit during our sample period, focusing only on continuously-operating generating units plus Huntington Beach units 3 and 4 (which operated through most of our sample period, but were converted to synchronous condensers in 2013). We explore entry and exit further in the Online Appendix, arguing that exclude the units that enter or exit during our sample period is unlikely to bias our results.

Sample graphs of the coefficients from these pre-period unit-level regressions are shown in Figure 4. We show twelve units: the four largest units for each of three technologies. As can be seen in Panel A, the combined cycle plants tend to turn on, and even reach capacity, at fairly low levels of system demand. These units are generally new, large, and efficient. The combustion turbines in Panel B are turned on at higher levels of demand and have much smaller capacity. Finally, the boilers (Panel C), which are generally large and old, are turned on only at high levels of system demand.

For the post-period, we use data from February 1, 2012 through January 31, 2013. These are the first twelve months after the SONGS closure. While it would be interesting to examine longer-run changes in the market (which will include adaptation responses, such as new capital investment), our estimates would become less credible as we used data further into the future. ${ }^{8}$

\subsection{Merit-Order and Out-of-Merit Effects}

We thus have a set of coefficients $\alpha$ for each of 21 bins at 184 generating units in 2 time periods, for a total of over 7,000 coefficients. We summarize them as follows. We define the "merit-order" change in generation at a given unit caused by the SONGS closure as: maintaining the ordering of units along the marginal cost curve, while requiring an additional 2,150 megawatt hours of generation to fill the SONGS gap. Then the merit-order change across all bins $b$ and all generating units $j$ in a geographic region $\left(J_{\text {North }}\right.$ or $\left.J_{\text {South }}\right)$ is:

$$
\sum_{b>2} \sum_{j \in J}\left(\alpha_{b j}^{p r e}-\alpha_{b-2, j}^{p r e}\right) \cdot \theta_{b}^{p o s t}
$$

\footnotetext{
${ }^{8}$ In the Online Appendix, we include results estimated with a post-period which goes through June 30, 2013, and the main results are similar but somewhat attenuated, as expected.
} 
where $\theta_{b}^{\text {post }}$ is the fraction of hours that system-wide demand was in bin $b$ during the postperiod. ${ }^{9}$

The "out-of-merit" effect is the change in generation from the pre-period to the post-period, conditional on a given level of system demand:

$$
\sum_{b} \sum_{j \in J}\left(\alpha_{b j}^{p o s t}-\alpha_{b j}^{p r e}\right) \cdot \theta_{b}^{p o s t}
$$

For ease of calculating standard errors, we estimate equation (2) at the regional, rather than generating unit level. This is numerically equivalent, since in the tables which follow we are reporting the linear sum of coefficients across units within a region. When estimating the standard errors, we cluster by sample month to allow for arbitary spatial correlation and serial correlation within sample month. To examine whether the monthly cluster was sufficiently long, we regressed the residuals on their lags. Beyond fifteen days, we estimate coefficients that are close to zero and not statistically significant.

Additionally, we evaluate the merit-order and out-of-merit changes for subsets of hours when transmission constraints are most likely to bind. These calculations are exactly the same as equations 3 and 4 except we use observations from only a subset of post-closure hours. We consider two such subsets, each totalling approximately $5 \%$ of hours. First, we define weekday summer afternoons as 2 p.m. to 5 p.m. in months June through September. Second, we define high demand hours when total CEMS generation was in the 13th quantile (greater than 13,837 MWh); this leaves approximately the same number of observations as in the weekday summer afternoon results. We verify that both definitions are highly correlated with congestion as defined by the price differential between North and South. They are also correlated with one another, with a simple correlation of 0.30 .

The primary assumption for these estimates is that the ordering of units along the marginal cost curve in 2012 would have been the same as in 2010 and 2011, had SONGS not closed. There are many reasons to think this is a reasonable assumption. These are all natural gas plants, so there is no inter-fuel substitution, and the ordering among plants is essentially a monotonic ordering by heat rate. Moreover, while there were large changes in hydroelectric and renewables generation in 2012, these changes would not have affected the ordering of the natural gas units. As such, we can attribute moves up the ordering to the need to fill in for SONGS, and we can attribute re-ordering of units to the transmission constraints caused

\footnotetext{
${ }^{9}$ Note that this cannot be calculated for $\mathrm{b}=1$ and $\mathrm{b}=2$, since $b-2$ would be undefined. In our sample, these levels of thermal generation do not appear in the post period, so in practice $\theta=0$. If they had appeared, one solution would have been to use $\theta_{3}=\theta_{1}+\theta_{2}+\theta_{3}$.
} 
by SONGS. In the Online Appendix, we explore each concern in greater depth, concluding that our estimates are largely unaffected by them.

\section{Regional Impacts}

\subsection{Impact on Generation}

Table 3 describes the effect of the SONGS closure on the geographic pattern of generation in California. The reported estimates are average hourly changes in MWh. Panel A reports effects for all hours during the twelve months following the closure. The merit-order change in generation is similar between the North and the South: the point estimate is 892 in the South, and 944 in the North. The Central California column represents many fewer plants, and accordingly a smaller in-order change (300 MWh). By design, the total merit-order effect is approximately equal to 2,150 MWh, the lost generation from SONGS. This geographic pattern reflects where in the state thermal resources are located. Without any transmission constraints, our estimates imply that about $40 \%$ of the lost output from SONGS would have been produced by plants located in Southern California.

The out-of-merit estimates show the displacement of generation from Northern generating units to Southern units. Relative to what we would have expected in a world without transmission constraints, the Southern units increased generation by $150 \mathrm{MWh}$, while the Northern units decreased by $140 \mathrm{MWh}$. To put this in perspective, the average plant-level capacity is around $380 \mathrm{MW}$ in the South and around $270 \mathrm{MW}$ in the North, so these effects are approximately the size of half of a plant.

The results are starker when the sample is limited to the hours in which transmission constraints are most likely to bind. On weekday summer afternoons (Panel B), the out-of-merit effect almost doubles, to a $237 \mathrm{MWh}$ increase in the South and $260 \mathrm{MWh}$ decrease in the North. In the $5 \%$ of hours with the highest level of system demand (Panel C), the out-ofmerit effect is an increase in the South of $431 \mathrm{MWh}$, and a decrease in the North of 381 MWh. Thus as much as $75 \%$ of the lost generation from SONGS was met by plants in Southern California. To get a sense of the magnitude, the out-of-merit effect is comparable to an increase in capacity factor of three percentage points in the South and a decrease of three percentage points in the North.

These results implicitly assume that the entire displaced SONGS generation (2,150 MWh) was met by in-state CEMS units. This is a reasonable approximation given the lack of 
responsiveness in all other categories of generation observed in Figure 3. The one potential exception is imports, which are responsive over some ranges of demand. To account for this, we calculated the merit-order impact on imports of a shock to total demand equal to 2,150 MWh, using the generation regression for imports. This exercise implies that around $25 \%$ of the lost generation from SONGS would have been replaced by imports. One could imagine adjusting the merit-order estimates in Panel A of Table 3 accordingly. For weekday summer afternoons and high demand hours, however, we find a very small response in imports, consistent with the visual evidence in Figure 3. On weekday summer afternoons, only 4 percent of the lost generation would have made up by imports, and in high demand hours it would have been less than 1 percent. While the merit-order effects depend on how responsive imports are, the out-of-merit effects do not, as imports did not change transmission constraints. Further details, discussion, and figures plotting post-period generation regressions by category are presented in the Online Appendix.

The table also reports standard errors. The merit-order changes are estimated with a high degree of statistical precision and all nine estimates are strongly statistically significant. The estimated out-of-merit changes are less precise, reflecting that whereas the merit-order changes are estimated using the pre-period only, the out-of-merit effects reflect differences in estimated coefficients between the pre-period and the post-period. It would have been unusual to observe this magnitude and pattern of out-of-merit effects due to chance alone. In the Online Appendix, we report results from a series of placebo tests aimed at providing some reassurance that these results are not driven by omitted variables or model misspecification. In particular, we repeat the analysis six times using the exact same specification, but with a different set of years. In the first placebo test, for example, we estimate the model as if SONGS had closed in January 2007 rather than January 2012. Overall, the estimated outof-merit effects in these other years do not follow the pattern observed in 2012. Some of the estimates are similar in size to our main results. However, when one looks closely at non-zero out-of-merit effects in other years, they tend to be driven by long outages. To demonstrate this, we show several diagnostics on the unit-level out-of-merit effects. In the years with the largest out-of-merit placebo effects, the standard deviation, skewness, and kurtosis are all substantially larger (in absolute terms) than in 2012, indicating large year-to-year changes in generation at a few individual plants rather than correlated changes in generation across many plants. 


\subsection{Impact on Costs}

We next quantify the change in the total cost of production associated with these generation impacts. To do so, we must first calculate the marginal cost for each generating unit. As is common in the literature, we calculate marginal cost using information on heat rates, fuel prices, and variable operations and maintenance costs (VOM): $M C_{j}=$ heat rate ${ }_{j}$. fuel price $_{j}+V O M_{j}$. For the unit-level heat rate, we divide the total heat input over our time frame (in MMBtus) by the total net generation (in MWhs). This abstracts from ramping rates, as is common in the literature. We obtain daily natural gas prices from Platts Gas Daily and calculate the average post-period price. We focus, in particular, on the PG\&E City Gate price for the North, and the SCG City Gate price for the South. For VOM, we assume 3.02 \$/MWh for combined cycle plants and $4.17 \$ / \mathrm{MWh}$ for all other plants (in $2009 \$$ ), following CEC (2010). The resulting marginal cost estimates range from $\$ 24$ for generating units with favorable heat rates to $\$ 81$ for units with high heat rates.

In Figure 5, we plot the marginal cost curve for electricity in California. We use our estimates of marginal cost for all thermal units. For the capacity of these units, we use the maximum observed hourly generation in our sample. For hydroelectric, renewables, and nuclear, we proxy for capacity using the average hourly generation in the post-period (February 2012 through January 2013), from CAISO. While these types of generation have higher rated capacities, the average generation in the post-period is more relevant given constraints set by weather conditions. We assume zero marginal cost for hydro and renewables production. For the marginal cost of nuclear units, we use a nuclear fuel cost estimate of $\$ 7.08$ per MWh (in 2012\$) from Table 8.4 of the EIA's Electric Power Annual (EIA 2012), plus a nuclear VOM estimate for California of $\$ 5.27$ (in 2009\$) from CEC (2010).

We overlay on the marginal cost curve a histogram of total hourly generation in the postperiod. In most hours, the marginal generating unit is a combined cycle natural gas unit, with marginal cost (given the average post-period natural gas price) of around 27 \$ $/ \mathrm{MWh}$. In high demand hours, however, the marginal unit is typically either a combustion turbine or a boiler (again, fueled by natural gas), with marginal cost around $40 \$ / \mathrm{MWh}$.

To quantify the cost impact of the SONGS closure we run regressions similar to the unit-level generation regressions, except the dependent variable is now the cost of generation rather than the quantity:

$$
\left(M C_{j} \cdot \text { generation }_{j t}\right)=\sum_{b}\left(\delta_{b j} \cdot \mathbb{1}\left\{\text { net system-wide demand } d_{t}=b\right\}\right)+\mu_{j t} .
$$


The advantage of using this regression is that we can again decompose the total change in cost into merit-order and out-of-merit changes. Results are given in Table 4. Taking a weighted average across all hours, the merit-order increase in total cost of thermal generation was $\$ 29,000$ in the South, $\$ 8,000$ in the ZP region, and $\$ 27,000$ in the North - totalling $\$ 63,000$ statewide each hour. The average cost implied is approximately 29 \$ $/ \mathrm{MWh}$.

It is worth noting that this estimate of $\$ 63,000$ assumes that none of the lost generation from SONGS was replaced by imports. As described above, imports made up approximately 25 percent of the lost generation on average, across all hours. Given that the California marginal cost curve is quite elastic in most hours, the marginal cost of out-of-state generation necessarily must have been close to the marginal cost of the in-state generation. As such, we expect our estimate of $\$ 63,000$ to be close to the true merit-order change in total cost.

The out-of-merit changes are also significant. While total cost increased by $\$ 7,100$ in the South and $\$ 500$ in ZP, it decreased by $\$ 3,000$ at Northern generating units because of the decrease in quantity. Systemwide, this implies an increase of $\$ 4,500$ each hour coming from the out-of-merit changes in generation. While lower-cost units were available in the North, they could not be used because of the transmission constraints and other physical limitations of the grid. This out-of-merit effect reflects not only North-South transmission constraints, but also local transmission constraints in and around San Diego and Los Angeles, as well as other physical limitations of the grid. As we discuss briefly later in the paper, part of the challenge with SONGS closing was that there was now very little generation in northern San Diego county that could be used to boost the voltage of electricity transmitted from far away. Maintaining some "reactive" power locally was another reason why units would have been operated out-of-merit.

Thus the total cost increase at thermal power plants statewide, including both merit-order and out-of-merit effects, is almost $\$ 68,000$ per hour. This amounts to a 13 percent increase in total in-state generation costs. ${ }^{10}$ As another point of comparison, the average post-period price in the California wholesale electricity market (quantity-weighted) was $32 \$ / \mathrm{MWh}$. Multiplying this by total quantity (i.e. 2,150 MWh) gives $\$ 68,000$ per hour. The two measures are quite close together because the supply curve is fairly elastic in most hours throughout the year. Thus the cost of the marginal generating unit is not very different from the cost of inframarginal units. Using our estimate of the marginal cost of California nuclear plants (described above) of $12.8 \$ /$ MWh implies that the marginal cost of generation at SONGS would have been around $\$ 28,000$ each hour. This difference in costs implies that

\footnotetext{
${ }^{10}$ To calculate this, we assume that the average hourly cost for residual thermal generation (i.e., not observed in the CEMS data) is equal to the average cost we observe in our sample.
} 
the SONGS closure increased the cost of generation by $\$ 350$ million in the first twelve months. Of this, the out-of-merit portion is $\$ 4,500$ per hour, implying a total of $\$ 40$ million in the first twelve months following the closure. Table 5 summarizes these total impacts. ${ }^{11}$

Panels B and $\mathrm{C}$ of Table 4 report estimates of the cost changes for weekday summer afternoons and high demand hours, when transmission constraints are more likely to bind. The merit-order effects are larger than in Panel A, because the marginal generating units at these hours are higher up on the marginal cost curve. The change is particularly high in the South, where the generation impacts were larger. The out-of-merit changes in total cost are also higher than in Panel A, reflecting a combination of larger out-of-merit changes in generation and higher marginal costs. The system-wide total change in thermal costs is approximately $\$ 78,000$ per hour on weekday summer afternoons, and around $\$ 84,000$ per hour in high demand hours. As we describe above, imports did not substantially increase in the weekday summer afternoon and high demand hours, so we expect these estimates to be close to the true total change in cost. For comparison, the average weekday summer afternoon wholesale price (quantity-weighted) was 49 \$ MWh. Multiplying this by SONGS capacity gives $\$ 106,000$ per hour. The same calculation for high demand hours (Panel C) also gives $\$ 106,000$ per hour. These measures are considerably higher than our estimate because supply is relatively inelastic during these hours; the marginal generating unit has a much higher cost than the inframarginal units.

\subsection{Impacts on Emissions}

In addition to the private cost of generation we calculate above, we quantify the impact of the generation changes on carbon dioxide emissions. Using the CEMS data, we calculate unit-specific carbon emissions rates. We then use the same type of regression as we used for the generation and cost changes, but now with carbon dioxide emissions, in metric tons, as the dependent variable:

$$
\left(\text { carbon_rate }_{j} \cdot \text { generation }_{j t}\right)=\sum_{b}\left(\lambda_{b j} \cdot \mathbb{1}\left\{\text { net system-wide demand } d_{t}=b\right\}\right)+\nu_{j t} .
$$

While California power plants are currently covered by a carbon cap and trade program, they were not yet covered in 2012. As a result, any increase in carbon dioxide emissions

\footnotetext{
${ }^{11}$ These numbers reflect our assumptions regarding VOM costs. We are assuming that VOM at SONGS is substantially higher than VOM at the natural gas plants that came online when SONGS closed. If we were to assume equal VOM, the total cost of replacing the lost generation from SONGS would rise by about $\$ 40$ million.
} 
caused by the SONGS closure would not have been offset. We estimate an increase of 1,030 tons per hour. ${ }^{12}$ For comparison, the average hourly total emissions at CEMS plants was around 3,800 tons in 2010 and 3,100 tons in 2011. The central value of the social cost of carbon used by the federal government for regulatory impact analysis is $32 \$ /$ ton (in $2007 \$$ ) (IWG 2013). For this cost of carbon, our estimates imply a social cost of the additional emissions of almost $\$ 320$ million, in 2013 dollars.

We also examine the impact on sulfur dioxide and nitrogen oxides emissions. Our estimates imply that the SONGS closure increased emissions of both pollutants. However, natural gas plants emit small enough amounts of these criteria pollutants that the implied economic cost of the change in emissions is small compared to the carbon dioxide impacts. See Muller and Mendelsohn (2012) for recent estimates of marginal damages. Moreover, a portion of NOx emissions are capped in the RECLAIM market around the Los Angeles area, so some of these increases may have been offset by other sectors.

\section{Plant-Level Impacts}

Our empirical approach generates estimates of merit-order and out-of-order effects not only at a regional level, but also for individual plants. Table 6 shows the plants that were most affected by the SONGS outage. In Panel A, we show the plants with the five largest meritorder increases in generation. All five are large combined-cycle plants with low marginal cost. As Figure 5 shows, in most hours the equilibrium is at a fairly elastic portion of the supply curve, with costs around 27 \$MWh. Panel B of Table 6 shows the largest positive out-of-merit increases, and Panel $\mathrm{C}$ the largest out-of-merit decreases. The largest increases tend to be in the South and the largest decreases tend to be in the North, matching the aggregate results in Table 3 .

The differences between the South and North are starker during hours when transmission constraints were most likely to bind. Table 7 shows the most affected plants during high demand hours. Results for weekday summer afternoons are similar and available in the Online Appendix. Not surprisingly, the merit-order increases are largest at plants with much higher marginal cost: around 40 \$ MWh. In Panel B, the largest out-of-merit increases are exclusively at Southern plants, as expected. Moreover, these are plants that were approximately on the margin: their marginal cost is comparable to the marginal cost of the plants

\footnotetext{
${ }^{12}$ We do not report the geographic breakdown nor the difference in high demand hours, although they match what one would expect given the generation changes in Table 3. Since carbon dioxide is a long-lived, global pollutant, these breakdowns are not relevant.
} 
in Panel A.

In Panel C, several of the largest out-of-merit decreases are at plants in the North. There are two important exceptions, however. The two largest out-of-merit decreases in high demand hours were at plants in the South: Alamitos and Redondo, both owned by AES. These two large plants were on the margin in high demand hours: they appear in Panel A as plants with large merit-order changes. Moreover, given their location in the South, they would have been expected to have out-of-merit increases. To illustrate the anomaly these plants represent, we show in Figure 6 estimated out-of-merit effects by plant for high demand hours, separated by region. The AES plants are shown with black lines, while all other plants are shown with orange lines. While the other Southern California plants generally exhibit positive out-ofmerit effects, the estimated out-of-order effects for two of the three AES plants are clearly large and negative.

We view the AES out-of-merit decreases as consistent with the exercise of market power. As it turns out, the AES plants were operated through a tolling agreement with JP Morgan Ventures Energy Corporation, a subsidiary of JPMorgan Chase. The Federal Energy Regulatory Commission has alleged market manipulation by JP Morgan at these and other plants. ${ }^{13}$ FERC asserted that JP Morgan engaged in twelve different manipulative bidding strategies between September 2010 and November 2012 in both the California and Midcontinent markets. Some of the strategies, particularly in 2011, were designed to lead the independent system operator to schedule the generating units even when it was uneconomical to do so, then to pay prices above the wholesale price through so-called make-whole payments. Other strategies, particularly in 2012, involved submitting extremely high bids but relying on the ISO's dynamic scheduling constraints to lead the bids to be accepted. For details on the individual strategies, see FERC (2013). In 2013, JP Morgan agreed to pay a civil penalty of $\$ 285$ million and to disgorge $\$ 125$ million in alleged unjust profits.

It would be interesting to use our results to calculate the profit earned by AES by their alleged behavior, potentially then comparing this number to the settlement with FERC. Several things prevent us from being able to do that. First, since FERC alleged market manipulation in both the pre- and post-periods, we do not know whether the out-of-merit decreases at Alamitos and Redondo are a result of unusually high generation in 2011 or withholding in 2012. Second, the settlement with JP Morgan is still relatively recent, so

\footnotetext{
${ }^{13}$ To understand FERC's charges against JP Morgan it is helpful to have a bit of broader legal context. Regulatory oversight of electricity is different than for many goods, in that it is illegal to exercise unilateral market power. FERC is charged with a statutory mandate dating back to 1935 which requires wholesale electricity prices to be "just and reasonable," allowing for the recovery of production costs and a "fair" rate of return. See Wolak (2005) for additional discussion.
} 
it is hard to compare behavior before and after the settlement. As more data become available from post-settlement, it might be possible to do more analysis. Finally, much of the manipulation alleged by FERC was aimed at earning revenues through exceptional dispatch and other out-of-market operations, and we do not observe these payments.

We do, however, re-examine our main results in light of the FERC investigation. In Table 8 we again present estimates of the regional impact (as in Table 3), but this time separating three plants owned by AES from the other Southern plants. As column (2) shows, the outof-merit increases in the Southern units are even larger than in Table 3, once the plants with alleged market manipulation are separated out. We believe this validates our overall approach in two important ways. First, it shows that our out-of-merit estimates do indeed show the effects of the transmission constraints between the Northern and Southern markets. Second, it suggests that our out-of-merit estimates can serve as a valuable diagnostic tool, pointing to generating units where one might suspect non-competitive behavior.

\section{Discussion}

In Section 7.1 we compare our estimates of the value of transmission with available estimates in the literature for the cost of relieving transmission congestion. Then in Section 7.2 we step back and think more broadly about Southern California Edison's decision to close SONGS.

\subsection{Benefits vs. Costs}

Of the estimated $\$ 350$ million in increased generation costs, we attribute $\$ 40$ million to transmission constraints and other physical limitations of the grid. This reflects Southern plants operating too much, Northern plants operating too little, and intra-regional misallocation of generation across units. When the decision was made to close SONGS, it still had ten years left on its current operating license with the NRC. ${ }^{14}$ Over this ten-year horizon with a $1 \%$ discount rate (Office of Management and Budget, 2013), the annual cost of $\$ 40$ million implies a present discounted value of $\$ 380$ million.

It is interesting to compare this $\$ 380$ million, which reflects the potential benefit from additional transmission capacity, with cost estimates. There are several ways these transmission

\footnotetext{
${ }^{14}$ Reactor number two was licensed through February 2022, and reactor number three was licensed through November 2022. See Appendix A of NRC (2012).
} 
constraints could be relaxed. One approach would be to build an additional high-voltage $(500-\mathrm{kV})$ transmission line along the existing 'Path 15' corridor, an 84-mile path connecting Northern and Southern California. The advantage of increasing capacity of existing transmission lines is that it avoids much of the siting challenges inherent in opening new corridors. A similar project in Path 15 was completed in 2004 and cost almost $\$ 370$ million. ${ }^{15}$

Another alternative would have been to add new generation capacity in Southern California. Construction costs for a conventional combined-cycle natural gas plant in California are about $\$ 1100$ per kilowatt (EIA 2013B), so to build a plant that could replace the entire $2,150 \mathrm{MWs}$ from SONGS would cost about $\$ 2.4$ billion. This is considerably larger than the implied cost of the transmission constraints, but, of course, a new plant would both relax the transmission constraints and generate electricity.

There may also be lower-cost alternatives available. Part of the challenge with the SONGS closure was voltage regulation. Electricity gradually drops in voltage when it is transmitted long distances, so some local generation is necessary to complement electricity produced far away. Much of the attention since the SONGS closure has been on adding local generation, and in particular, on adding generation that provides "reactive" power that maintains voltage, making it possible to bring in more power produced far away. For example, in 2013 two generators at Huntington Beach Plant were converted to synchronous condensers to provide local voltage support. According to CAISO (2013A) this project cost $\$ 15$ million, making it relatively inexpensive compared to capacity and generation additions.

Thus overall it appears there are some infrastructure investments that would pass a costbenefit test. Expanding 'Path 15' appears to just barely pass a cost-benefit test, but local voltage support investments like the Huntington Beach Project are inexpensive enough to pass a cost-benefit test even if they only partially relieve the constraints. CAISO seems to agree with this assessment and since 2013 has been taking steps to expand local transmission capacity in and around San Diego County (CAISO 2013E).

\subsection{The Decision to Close SONGS}

More broadly, an appealing feature of our analysis is that it provides some of the information necessary to step back and evaluate whether it was socially efficient to retire SONGS. This depends on the value of the electricity that SONGS would have generated during the ten

\footnotetext{
${ }^{15}$ See the Western Area Power Administration's 2004 "Path 15 Upgrade Project" Fact Sheet at http://www.wapa.gov/sn/ops/transmission/path15/factSheet.pdf. We multiplied the construction cost by 1.20 to reflect year 2013 dollars.
} 
years left on its license, the fixed costs of repairing the plant and keeping it open, and all relevant externalities.

We find that the SONGS closure increased generation costs by $\$ 350$ million during the first twelve months, after accounting for avoided generation costs at SONGS. In addition, we find that closing SONGS caused carbon dioxide emissions to increase by an amount worth almost $\$ 320$ million. Thus, the economic cost of closing SONGS was about $\$ 670$ million in the first twelve months.

These costs must be compared with the benefits of closing the plant. Although the marginal cost of nuclear generation is low, its annual operations and maintenance costs are substantial, about $\$ 340$ million per year. ${ }^{16}$ In addition, there are important external costs associated with operating a nuclear power plant. Some were concerned, for example, that SONGS' troubles signaled increased risk of a major accident. Quantifying these risks is very difficult, but even a tiny probability of a catastrophic nuclear accident could outweigh the benefits of keeping the plant open.

Another important practical complication is that it was not clear when the plant would have been able to reopen. When Southern California Edison made the decision to permanently retire the plant, they were waiting to hear from the Nuclear Regulatory Commission whether they would ever be allowed to restart SONGS. The NRC had already warned SCE that it might be a year or more before a final decision would be made, implying real uncertainty about timing and about the cost of any required repairs. Given this uncertainty, Southern California Edison's decision appears to pass a private cost-benefit test.

It is also worth noting that the costs of closing the plant would have been much higher if natural gas prices had not fallen so much in recent years. At the level of natural gas prices seen in 2007, for instance, the increase in generation costs from the closure of SONGS would have been two or three times larger. This is in line with the observation made by some industry analysts that the shale gas boom has severely worsened the economics of existing nuclear plants. Along a similar vein, the convexity of the supply curve implies that costs could have been much higher had the system been further stressed by an extended period of hotter-than-average weather or an outage at another major power plant.

\footnotetext{
${ }^{16}$ The Cost of Generation Model from CEC (2010) reports an annual fixed O\&M cost for California nuclear plants of $147.7 \$ / \mathrm{kW}$-yr, in 2010 dollars. We multiplied this by SONGS' capacity of $2,150 \mathrm{MW}$ and we translated into current dollars. This number closely matches regulatory documents, in which SCE had forecast fixed O\&M costs of $\$ 346$ million per year prior to the closure (CPUC 2012).
} 


\section{Conclusion}

Our paper uses evidence from the SONGS closure to quantify the value of electricity transmission in California. We find that the SONGS closure increased the private cost of electricity generation in California by about $\$ 350$ million during the first twelve months. Of this, $\$ 40$ million reflects transmission constraints and other physical limitations of the grid that necessitated that a high fraction of lost generation be met by plants located in the Southern part of the state. These constraints also increased the scope for market power, and we find evidence consistent with one company acting non-competitively.

We also find that the closure had a surprisingly large environmental impact. Because virtually all of the lost production from SONGS was replaced by natural gas generation, the closure increased carbon dioxide emissions by 9 million metric tons during the first twelve months. At $\$ 35$ per ton, the economic cost of these emissions is almost $\$ 320$ million. A large fraction of the world's nuclear plants are beginning to reach retirement age, and it is important to take these external costs into account as decisions are made about whether or not to extend the operating lives of these plants.

The analysis corroborates long-held views about the importance of transmission constraints in electricity markets (Bushnell, 1999; Borenstein, Bushnell and Stoft, 2000; Joskow and Tirole, 2000) and contributes to a growing broader literature on the economic impacts of infrastructure investments (Jensen, 2007; Banerjee, Duflo and Qian, 2012; Borenstein and Kellogg, 2014; Donaldson, Forthcoming). Infrastructure facilitates trade and reduces price dispersion, but it also affects market structure, and this is true not only for electricity but also for a broad range of tradable goods (Ryan, 2013).

Our results also illustrate the challenges of designing deregulated electricity markets. Wolak (2014) argues that while competition may improve efficiency relative to regulated monopoly, it also introduces cost in the form of greater complexity and need for monitoring. Transmission constraints add an additional layer to this complexity, by implicitly shrinking the size of the market. Constraints increase the scope for non-competitive behavior, but only for certain plants during certain high-demand periods. Understanding and mitigating market power in these contexts is difficult and requires an unusually sophisticated regulator.

Despite these challenges, the experience in California in 2012 also provides some cause for optimism. An enormous generating facility closed suddenly and unexpectedly during a year with low hydroelectric generation, yet there was essentially no disruption in supply and wholesale prices remained steady. In part, these 'steady' prices were only an illusion, driven 
by a lucky coincidence in the form of decreased natural gas prices. However the experience also points to a more mature, more flexible market that, although imperfect, provides many of the right incentives for generation and investment. 


\section{References}

Allaz, Blaise, and Jean-Luc Vila. 1993. "Cournot Competition, Forward Markets and Efficiency." Journal of Economic Theory, 59(1): 1-16.

Banerjee, Abhijit, Esther Duflo, and Nancy Qian. 2012. "On the Road: Access to Transportation Infrastructure and Economic Growth in China." NBER Working Paper $1789 \%$

Birge, John, Ali Hortaçsu, Ignacia Mercadal, and Michael Pavlin. 2013. "The Role of Financial Players in Electricity Markets: An Empirical Analysis of MISO." Working paper.

Borenstein, Severin, and James Bushnell. 1999. "An Empirical Analysis of the Potential for Market Power in California's Electricity Industry." The Journal of Industrial Economics, 47(3): 285-323.

Borenstein, Severin, and Ryan Kellogg. 2014. "The Incidence of an Oil Glut: Who Benefits from Cheap Crude Oil in the Midwest?" Energy Journal, 35: 15-33.

Borenstein, Severin, James B Bushnell, and Frank A Wolak. 2002. "Measuring Market Inefficiencies in California's Restructured Wholesale Electricity Market." American Economic Review, 92(5): 1376-1405.

Borenstein, Severin, James Bushnell, and Steven Stoft. 2000. "The Competitive Effects of Transmission Capacity in a Deregulated Electricity Industry." RAND Journal of Economics, 31(2): 294-325.

Bushnell, James. 1999. "Transmission Rights and Market Power." The Electricity Journal, 12(8): $77-85$.

Bushnell, James B, Erin T Mansur, and Celeste Saravia. 2008. "Vertical Arrangements, Market Structure, and Competition: An Analysis of Restructured U.S. Electricity Markets." The American Economic Review, 98(1): 237-266.

California Energy Commission (CEC). 2010. "Cost of Generation Model Version 2." Accessed from http://www.energy.ca.gov/2010publications/CEC-200-2010-002/.

California Energy Commission (CEC). 2012. "Summer 2012 Electricity Supply and Demand Outlook."

California Independent System Operator (CAISO). 2012. "Q2 2012 Report on Market Issues and Performance." Accessed from 
http://www.caiso.com/Documents/2012SecondQuarterReport-MarketIssues-PerformanceAugust2012.pdf.

California Independent System Operator (CAISO). 2013a. "Amendments to RMR Agreement with AES Huntington Beach, LLC." Accessed from http://www.caiso.com/Documents/Jun3_2013_Amendment_AESHuntingtonBeachReliability MustRunAgreement_ER13-351_ER13-1630.pdf.

California Independent System Operator (CAISO). 2013b. "Annual Report on Market Issues and Performance, 2012." Accessed from http://www.caiso.com/Documents/2012AnnualReport-MarketIssue-Performance.pdf.

California Independent System Operator (CAISO). 2013c. "Daily Renewables Watch." Accessed from http://content.caiso.com/green/renewableswatch.html.

California Independent System Operator (CAISO). 2013d. "Master CAISO Control Area Generating Capability List." Accessed from http://www.caiso.com/Documents/GeneratingCapabilityList.xls.

California Independent System Operator (CAISO). 2013e. "Summer Loads and Resources Assessment, 2013." Accessed from https://www.caiso.com/Documents/2013SummerLoads_ResourcesAssessment.pdf.

California Public Utilities Commission (CPUC). 2012. "Decision on Test Year 2012 General Rate Case for Southern California Edison Company." Accessed from http://www.edison.com/files/2012GeneralRateCaseProposedDecision101912.pdf.

Cardell, Judith B, Carrie Cullen Hitt, and William W Hogan. 1997. "Market Power and Strategic Interaction in Electricity Networks." Resource and Energy Economics, 19(1): 109-137.

Cullen, Joseph, and Erin T. Mansur. 2013. "Will Carbon Prices Reduce Emissions in the U.S. Electricity Industry? Evidence from the Shale Gas Experience." Working Paper.

Davis, Lucas W. 2012. "Prospects for Nuclear Power." The Journal of Economic Perspectives, 26(1): 49-66.

Davis, Lucas W, and Catherine Wolfram. 2012. "Deregulation, Consolidation, and Efficiency: Evidence from U.S. Nuclear Power." American Economic Journal: Applied Economics, 4(4): 194-225.

Donaldson, Dave. Forthcoming. "Railroads of the Raj: Estimating the Impact of Transportation Infrastructure." American Economic Review. 
Edison Electric Institute. 2014. "Transmission Projects: At a Glance." Accessed from http://www.eei.org/issuesandpolicy/transmission/Documents/Trans_Project_lowres_bookmarked.pdf.

Energy Information Administration (EIA). 2012. "Electric Power Annual." Accessed from http://www.eia.gov/electricity/annual/.

Energy Information Administration (EIA). 2013a. "Monthly Energy Review." Accessed from http://www.eia.gov/totalenergy/data/monthly/pdf/mer.pdf.

Energy Information Administration (EIA). 2013b. "Updated Capital Cost Estimates for Utility Scale Electricity Generating Plants." Accessed from http://www.eia.gov/forecasts/capitalcost/pdf/updated_capcost.pdf.

Fabrizio, Kira R, Nancy L Rose, and Catherine D Wolfram. 2007. "Do Markets Reduce Costs? Assessing the Impact of Regulatory Restructuring on U.S. Electric Generation Efficiency." The American Economic Review, 97(4): 1250-1277.

Federal Energy Regulatory Commission (FERC). 2013. "Order Approving Stipulation and Consent Agreement, Docket Nos IN11-8-000 and IN13-5-000." Accessed from http://www.ferc.gov/CalendarFiles/20130730080931-IN11-8-000.pdf.

Holland, Stephen P, and Erin T Mansur. 2008. "Is Real-Time Pricing Green? The Environmental Impacts of Electricity Demand Variance." The Review of Economics and Statistics, 90(3): 550-561.

Hortacsu, Ali, and Steven L Puller. 2008. "Understanding Strategic Bidding in MultiUnit Auctions: A Case Study of the Texas Electricity Spot Market." The RAND Journal of Economics, 39(1): 86-114.

Interagency Working Group on Social Cost of Carbon, United States Government (IWG). 2013. "Technical Support Document: - Technical Update of the Social Cost of Carbon for Regulatory Impact Analysis - Under Executive Order 12866." Accessed from http://www.whitehouse.gov/sites/default/files/omb/assets/inforeg/technicalupdate-social-cost-of-carbon-for-regulator-impact-analysis.pdf.

Ito, Koichiro. 2014. "Do Consumers Respond to Marginal or Average Price? Evidence from Nonlinear Electricity Pricing." American Economic Review, 104(2): 537-663.

Jensen, Robert. 2007. "The Digital Provide: Information (Technology), Market Performance, and Welfare in the South Indian Fisheries Sector." Quarterly Journal of Economics, 122(3): 879-924. 
Joskow, Paul L, and Edward Kahn. 2002. "A Quantitative Analysis of Pricing Behavior in California's Wholesale Electricity Market During Summer 2000." Energy Journal, 23(4): 1-35.

Joskow, Paul L, and Jean Tirole. 2000. "Transmission Rights and Market Power on Electric Power Networks." The Rand Journal of Economics, 450-487.

Kotchen, Matthew J., and Erin T Mansur. 2013. "How Stringent is the EPA's Proposed Carbon Pollution Standard for New Power Plants?" Working Paper.

Mansur, Erin, and Matthew White. 2012. "Market Organization and Efficiency in Electricity Markets." Working Paper.

Mansur, Erin T. 2007. "Do Oligopolists Pollute Less? Evidence From A Restructured Electricity Market." The Journal of Industrial Economics, 55(4): 661-689.

Muller, Nicholas Z, and Robert Mendelsohn. 2012. "Efficient Pollution Regulation: Getting the Prices Right: Corrigendum (Mortality Rate Update)." American Economic Review, 102(1): 613-16.

North American Electric Reliability Corporation (NERC). 2012. "2012 Summer Reliability Assessment." Accessed from http://www.nerc.com/files/2012sra.pdf.

Nuclear Regulatory Commission (NRC). 2012. "2012-2013 Information Digest." Accessed from http://pbadupws.nrc.gov/docs/ML1224/ML12241A166.pdf.

Office of Management and Budget. 2013. "Discount Rates for Cost-Effectiveness, Lease Purchase, and Related Analyses, Circular A-94."

Puller, Steven L. 2007. "Pricing and Firm Conduct in California's Deregulated Electricity Market." The Review of Economics and Statistics, 89(1): 75-87.

Ryan, Nicholas. 2013. "The Competitive Effects of Transmission Infrastructure in the Indian Electricity Market." Working Paper.

Southern California Edison. 2013. "Press Release: Southern California Edison Announces Plans to Retire San Onofre Nuclear Generation Station." Accessed from http://www.songscommunity.com/news2013/news060713.asp.

Wolak, Frank. 2012. "Measuring the Competitiveness Benefits of a Transmission Investment Policy: The Case of the Alberta Electricity Market." Working Paper.

Wolak, Frank. 2014. "Regulating Competition in Wholesale Electricity Supply." In Economic Regulation and Its Reform., ed. Nancy Rose. University of Chicago Press. 
Wolak, Frank A. 2005. "Lessons from the California Electricity Crisis." In Electricity Deregulation: Choices and Challenges., ed. James M Griffin and Steven L Puller. University of Chicago Press.

Wolfram, Catherine D. 1999. "Measuring Duopoly Power in the British Electricity Spot Market." American Economic Review, 805-826. 
Figure 1: Weekly Maximum Prices, South versus North

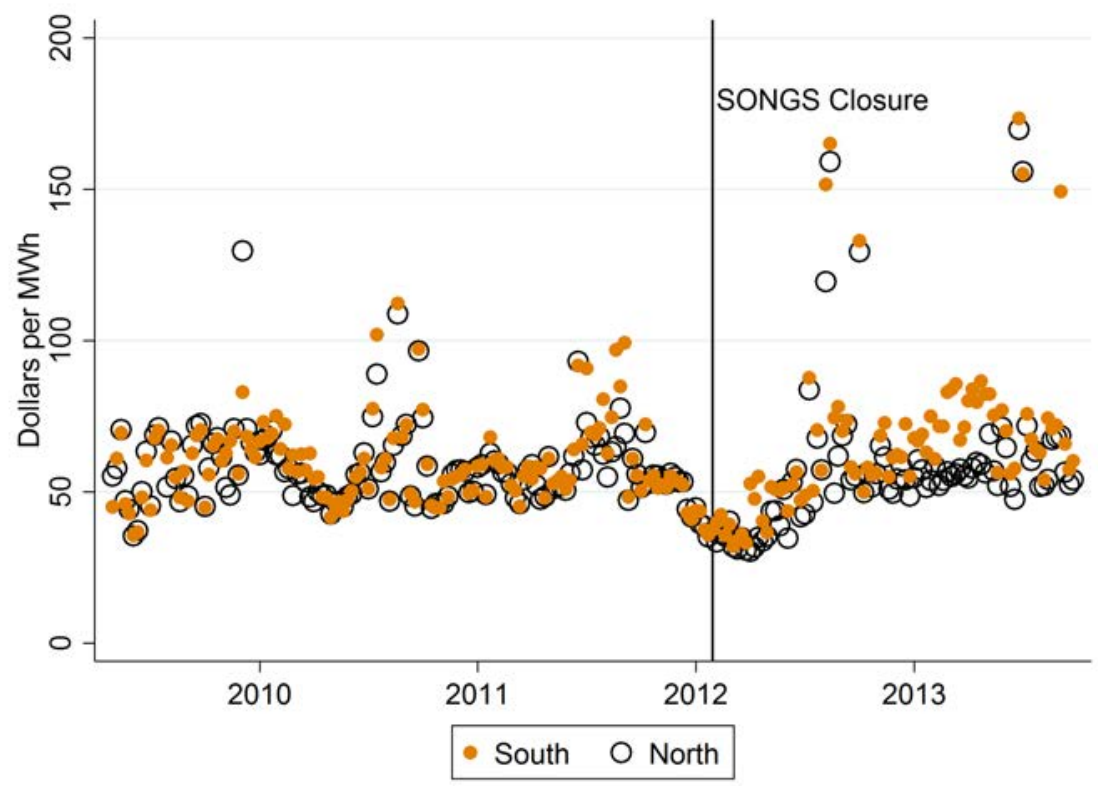

Note: This figure plots maximum hourly wholesale electricity prices by week for Northern and Southern California during the period 2009 to 2013. The vertical line indicates January 31, 2012, the day the second SONGS unit was shut down. One outlier in 2009, with both North and South prices greater than 400, has been dropped. North and South are defined by the Path-15 transmission interconnection. 
Figure 2: Price Differential, South versus North

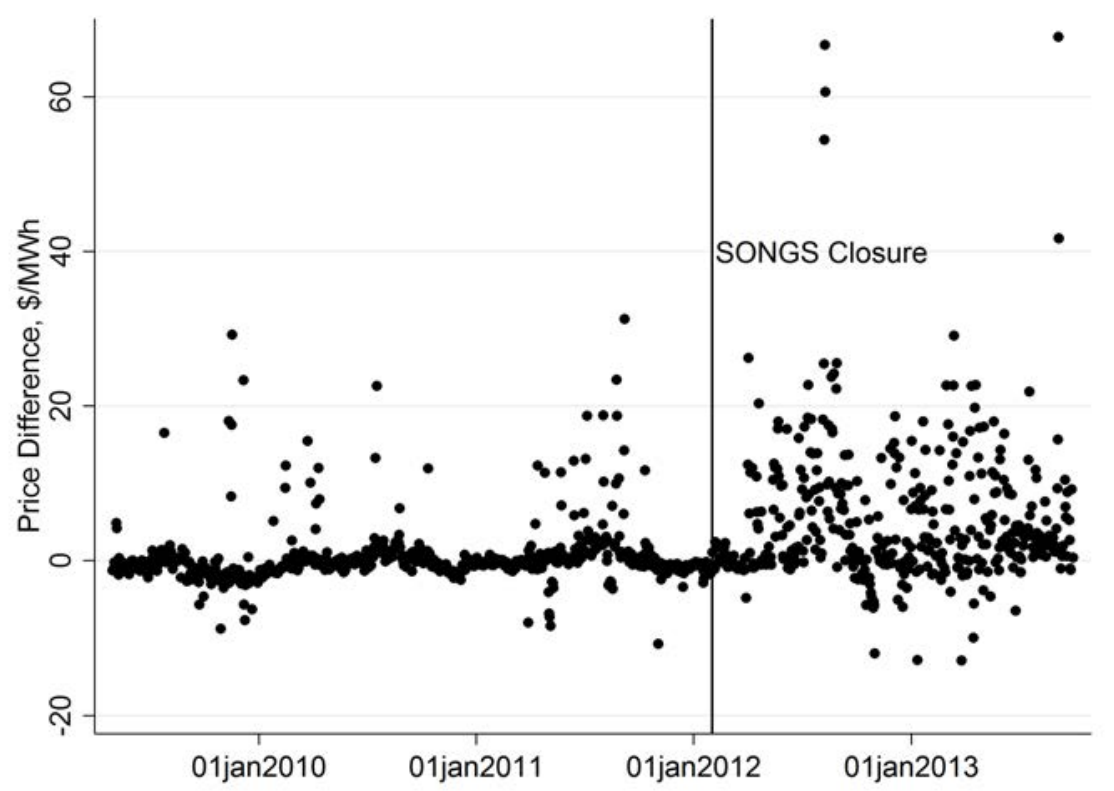

Note: This figure plots daily wholesale electricity price differentials at 3 pm between May 2009 and September 2013. Weekends are excluded. For each day, we calculate the price difference between Southern and Northern California. The vertical line indicates January 31,2012 , the day the second SONGS unit was shut down. 
Figure 3: Generation Regressions by Category
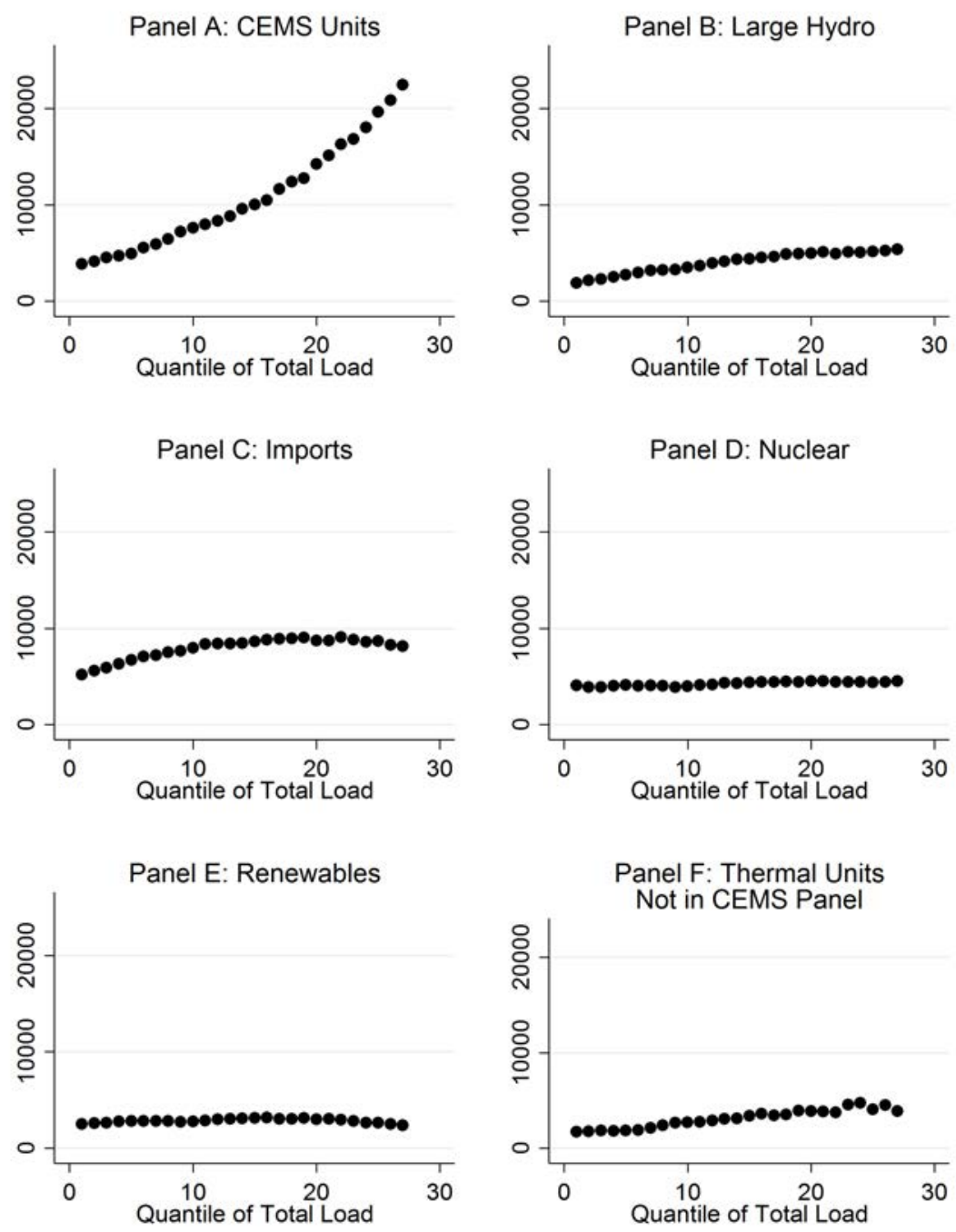

Note: These figures plot the coefficients from six separate regressions. As described in detail in the text, these regressions are estimated using hourly data from the two years prior to the closure of SONGS. The x-axis is total generation from all sources (in quantiles) and the $y$-axis is average generation, in MWh, for that category of generation. For the non-CEMS thermal units in Panel F, we have subtracted total CEMS generation in our balanced panel from total thermal generation as reported by CAISO. 
Figure 4: Generation Regressions by Individual Unit

Panel A: Combined Cycle Units
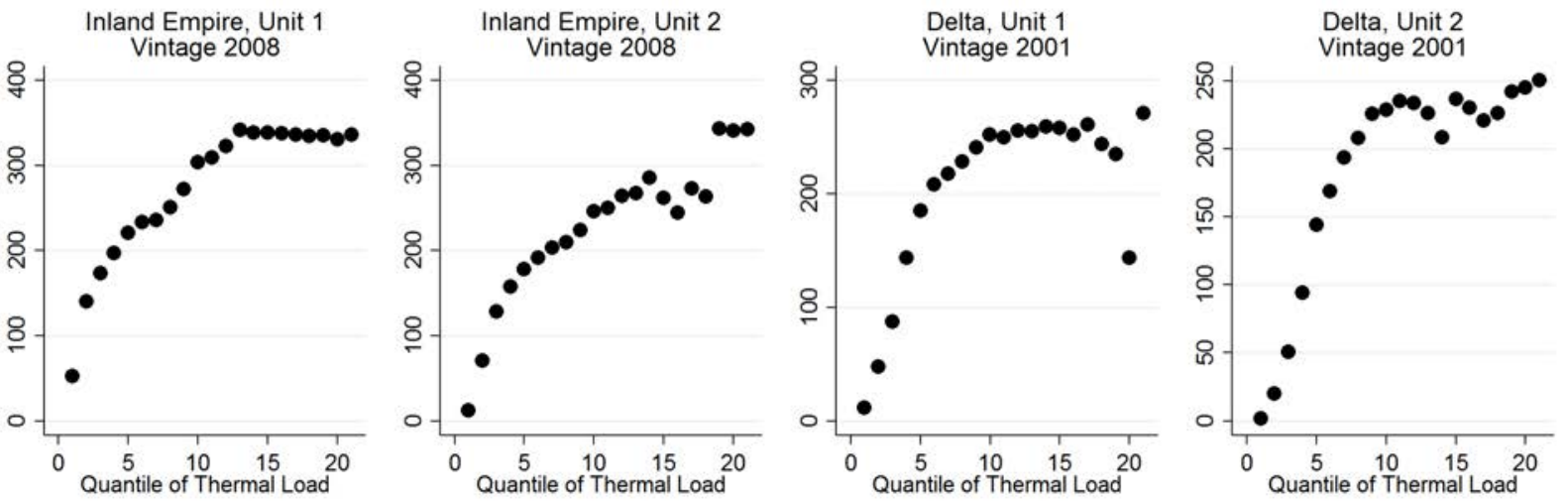

Panel B: Combustion Turbine Units
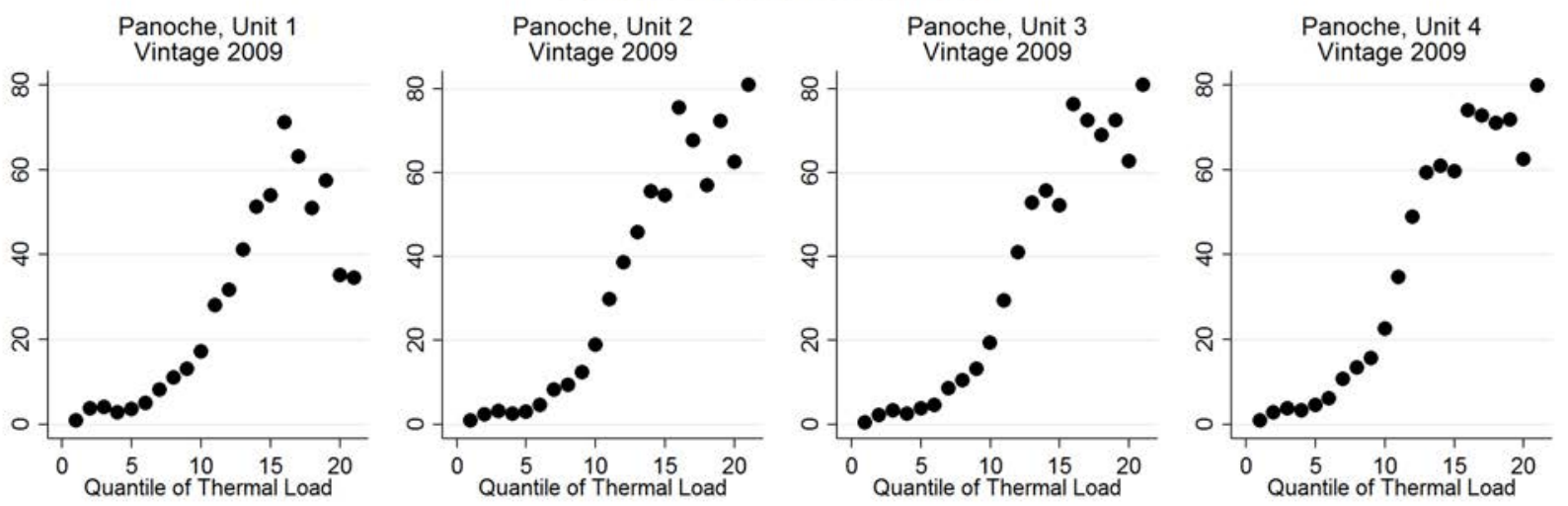

Panel C: Boiler Units
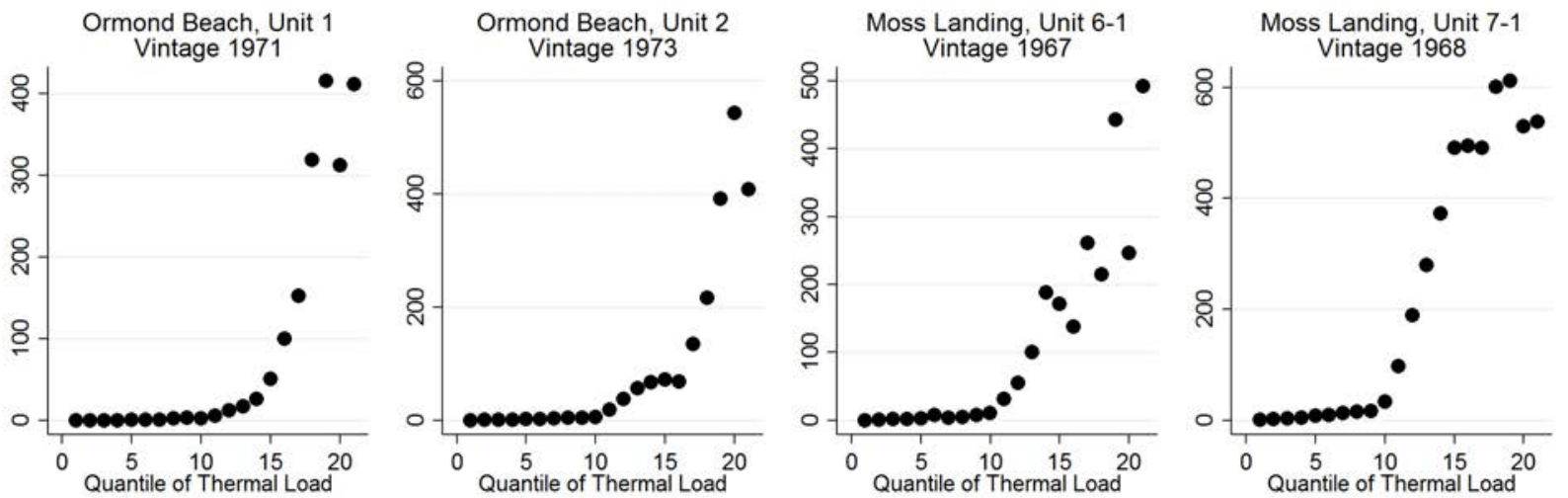

Note: These figures plot the coefficients from 12 separate unit-level generation regressions, for the four largest units within three technology types as indicated in the panel headings. As described in detail in the text, these regressions are estimated using hourly data from April 20, 2010 until December 31, 2011. The x-axis is total generation from all units in the CEMS panel (in quantiles) and the $\mathrm{y}$-axis is average generation, in MWh, for that individual unit. 
Figure 5: The Marginal Cost of Electricity in California, 2012

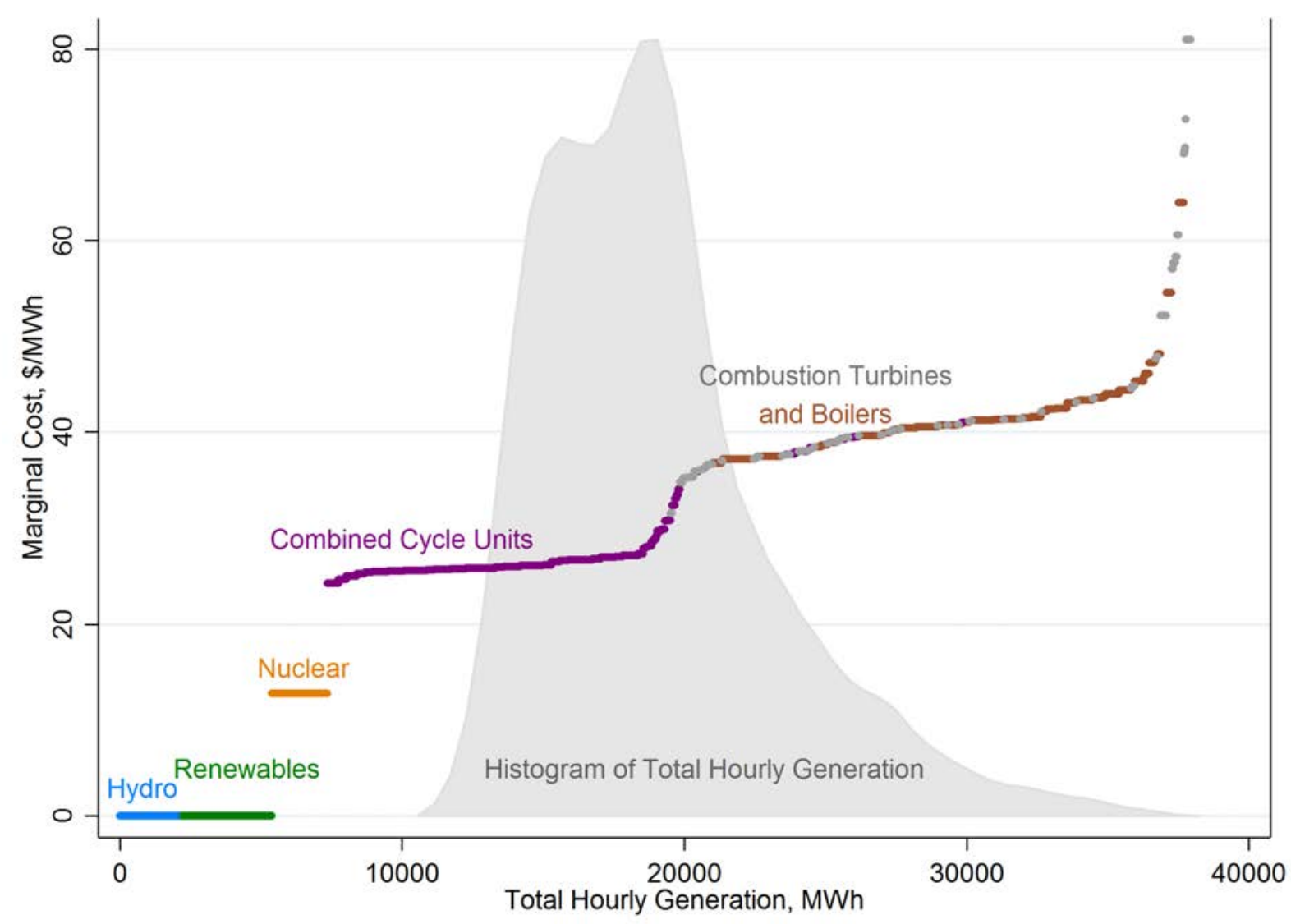

Note: This figure was constructed by the authors using their measures of marginal cost and capacity for electricity generating resources in the state of California in 2012. Imports are not included. All dollar amounts in year 2013 dollars. To construct marginal cost for natural gas units, we use unit-specific heat rates, the average natural gas price (separated by region), and California Energy Commission estimates for variable O\&M costs. For details, see the text. For the capacity of natural gas units (i.e. the width of each step), we use the maximum observed hourly generation in our sample. For hydro, renewables (including wind, solar, geothermal, and small hydro), and nuclear capacity, we use average hourly generation in 2012 . For the marginal cost of nuclear generation, we use an EIA estimate of fuel costs of $7.08 \$ / \mathrm{MWh}$ (in 2012\$) and a CEC estimate of nuclear variable O\&M of $5.27 \$ / \mathrm{MWh}$ (in 2009\$). Biomass/biogas are not shown, as marginal cost numbers are not available. This marginal cost of biomass generation is likely in the range of the combined cycle units with an average production over this period of around $500 \mathrm{MWh}$. 
Figure 6: Plant-Level Out-of-Merit Changes in High Demand Hours

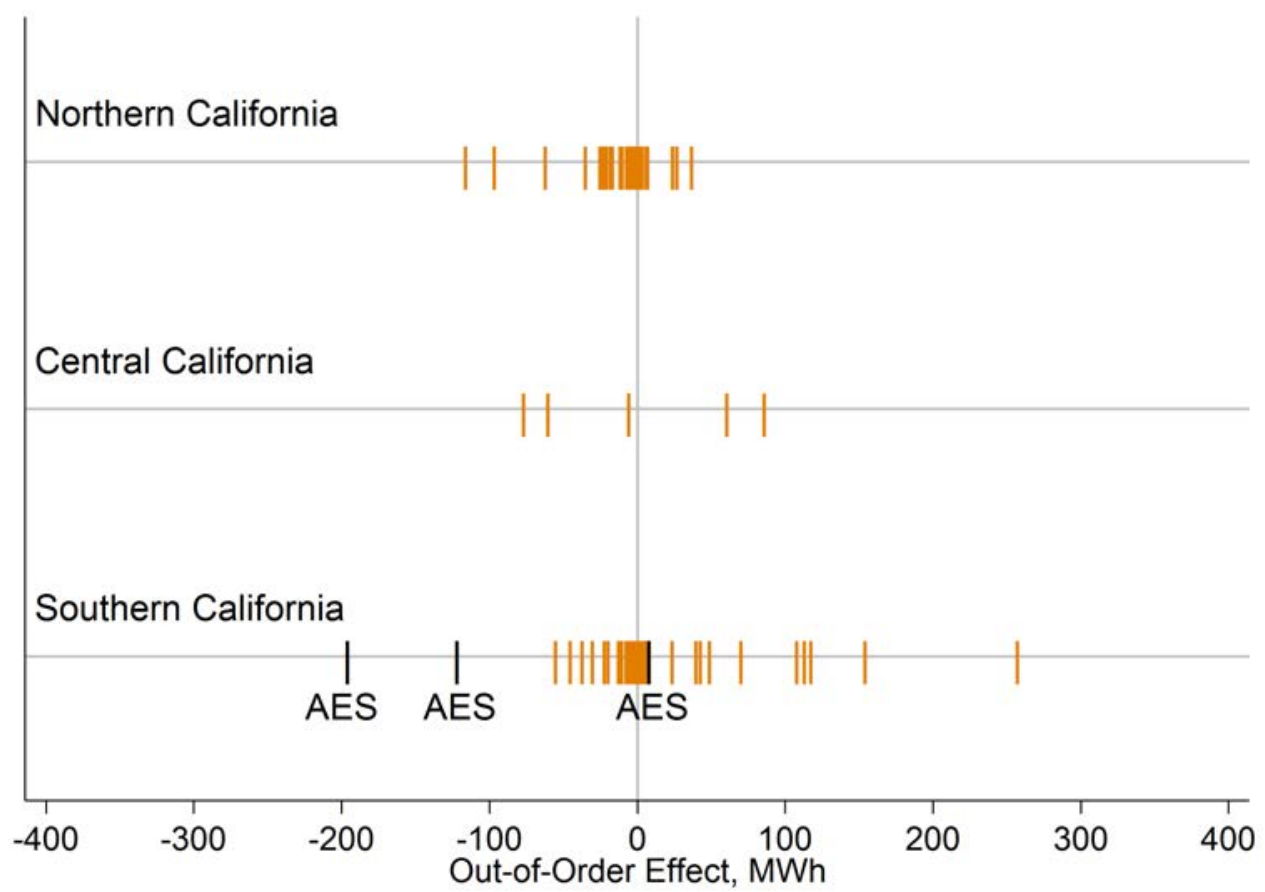

Note: This figure plots plant-level hourly average out-of-merit changes by region. High demand hours are defined as hours when total CEMS generation was in the 13th quantile (13,837 MWh) or greater. Estimates for AES-owned plants are indicated with black lines, while all other estimates are orange. Details on the calculations are given in the text. 
Table 1: California Electricity Generation By Source, 2011

\begin{tabular}{|c|c|c|}
\hline Category & Subcategory & Percentage \\
\hline \multirow[t]{4}{*}{ Fossil Fuels } & Natural Gas & 44.3 \\
\hline & Coal & 1.0 \\
\hline & Other Fossil Fuels & 1.7 \\
\hline & Total & 47.0 \\
\hline \multirow[t]{3}{*}{ Nuclear } & San Onofre & 9.0 \\
\hline & Diablo Canyon & 9.2 \\
\hline & Total & 18.3 \\
\hline \multirow[t]{6}{*}{ Renewables } & Hydroelectric & 21.1 \\
\hline & Geothermal & 6.3 \\
\hline & Wind & 3.9 \\
\hline & Solar (PV and Thermal) & 0.4 \\
\hline & Other Renewables & 3.0 \\
\hline & Total & 34.7 \\
\hline \multicolumn{2}{|l|}{ Total } & 100.0 \\
\hline \multicolumn{3}{|c|}{$\begin{array}{l}\text { Note: These data come from the U.S. Department of Energy Power Plant Operations } \\
\text { Report, which reports net generation from all electric generating plants larger than one } \\
\text { megawatt. We include all facilities operating in California. "Other Fossil Fuels" includes } \\
\text { petroleum coke, distillate petroleum, waste oil, residual petroleum, and other gases. "Other } \\
\text { Renewables" includes wood, wood waste, municipal solid waste, and landfill gas. }\end{array}$} \\
\hline
\end{tabular}


Table 2: California Electricity Generation, 2011-2012

\begin{tabular}{|c|c|c|c|}
\hline & $\begin{array}{c}\text { Average Monthly } \\
\text { Generation, } \\
\text { Million MWh } \\
2011\end{array}$ & $\begin{array}{c}\text { Average Monthly } \\
\text { Generation, } \\
\text { Million MWh } \\
2012\end{array}$ & Change \\
\hline \multicolumn{4}{|c|}{ Panel A: By Generation Category, EIA Data } \\
\hline Natural Gas & 7.41 & 9.97 & 2.56 \\
\hline Wind & 0.65 & 0.81 & 0.17 \\
\hline Solar (PV and Thermal) & 0.07 & 0.12 & 0.04 \\
\hline Other Renewables & 0.50 & 0.53 & 0.02 \\
\hline Geothermal & 1.05 & 1.04 & 0.00 \\
\hline Coal & 0.17 & 0.11 & -0.05 \\
\hline Other Fossil Fuels & 0.29 & 0.22 & -0.08 \\
\hline Hydroelectric & 3.54 & 2.28 & -1.25 \\
\hline Nuclear & 3.06 & 1.54 & -1.51 \\
\hline
\end{tabular}

Panel B: By Type of Natural Gas Plant, EIA Data

\begin{tabular}{|c|c|c|c|}
\hline Independent Power Producer Non-Cogen & 2.63 & 4.48 & 1.85 \\
\hline Electric Utility & 2.24 & 2.98 & 0.73 \\
\hline Industrial Non-Cogen & 0.03 & 0.11 & 0.07 \\
\hline Commercial Non-Cogen & 0.02 & 0.02 & 0.00 \\
\hline Commercial Cogen & 0.14 & 0.13 & -0.01 \\
\hline Independent Power Producer Cogen & 1.37 & 1.36 & -0.01 \\
\hline Industrial Cogen & 0.99 & 0.90 & -0.09 \\
\hline \multicolumn{4}{|c|}{$\underline{\text { Panel C: By Generation Category, CAISO Data }}$} \\
\hline Thermal & 6.12 & 8.47 & 2.35 \\
\hline Imports & 5.45 & 5.77 & 0.32 \\
\hline Renewables & 2.11 & 2.25 & 0.14 \\
\hline Large Hydroelectric & 2.47 & 1.58 & -0.89 \\
\hline Nuclear & 3.07 & 1.55 & -1.51 \\
\hline
\end{tabular}

Note: This table reports the average monthly net electricity generation in California in 2011 and 2012, measured in million MWh. As described in the text, the EIA data describe all U.S. generating facilities with more than one megawatt of capacity. We include generation from all facilities in California. In Panel A, "Other Renewables" includes wood, wood waste, municipal solid waste, and landfill gas. "Other Fossil Fuels" includes petroleum coke, distillate petroleum, waste oil, residual petroleum, and other gases. Panel C describes electricity sold through the California Independent System Operator, including four categories of generation from inside California, and "imports" which includes all electricity coming from out of state. 


\section{Table 3: The Effect of the SONGS Closure on the Regional Pattern of Generation}

Average Hourly Change in Net Generation, By Region

$\begin{array}{ccc}\text { Southern } & \text { Central } & \text { Northern } \\ \text { California } & \text { California } & \text { California } \\ \text { (SP26) } & \text { (ZP26) } & \text { (NP15) }\end{array}$

Panel A: All Hours

$\begin{array}{lccr}\text { Merit-Order Change (MWh) } & 892 & 300 & 944 \\ & (18) & (15) & (18) \\ \text { Out-of-Merit Change (MWh) } & 150 & 20 & -140 \\ & (73) & (66) & (79)\end{array}$

Panel B: Weekday Summer Afternoons

Merit-Order Change (MWh)

$\begin{array}{ccc}1068 & 259 & 822 \\ (47) & (17) & (39) \\ & & \\ 237 & 76 & -260 \\ (144) & (61) & (119)\end{array}$

Panel C: High Demand Hours

Merit-Order Change (MWh)

1207

174

(30)

431

4

(144)

(57)

$-381$

Observations (Hour by Unit)

Number of Generating Units

Number of Plants

Total Capacity (MW)
$2,285,140$

94

42

15,922
944

Note: This table reports our estimates of the change in generation that resulted from the SONGS closure on January 31, 2012. We report both "merit-order" and "out-of-merit" effects. The merit-order calculation gives the increase in generation at marginal units, assuming 2,150 MWh of lost generation from SONGS. The out-ofmerit calculation gives the difference between actual and expected generation, as explained in the text. For all calculations our sample includes hourly observations between April 20, 2010 and January 31, 2013. We exclude generating units that enter or exit during the sample period. As indicated by the column headings, we report estimates for three California regions as defined by the Path-15 and Path-26 transmission interconnections. Panel A reports estimated impacts for all hours. Panel B reports estimates for 2 p.m. to 5 p.m. in months June through September. Panel C reports estimates for hours when total CEMS generation was in the 13th quantile $(13,837 \mathrm{MWh})$ or greater. Standard errors (in parentheses) are clustered by sample month. 


\section{Table 4: The Effect of the SONGS Closure on Thermal Generation Costs}

Average Hourly Change in Total Generation Cost, By Region

$\begin{array}{ccc}\text { Southern } & \text { Central } & \text { Northern } \\ \text { California } & \text { California } & \text { California } \\ \text { (SP26) } & \text { (ZP26) } & \text { (NP15) }\end{array}$

$(1)$

$(2)$

(3)

Panel A: All Hours

Merit-Order Change (\$000’s)

Out-of-Merit Change (\$000's)

Merit-Order Change (\$000's)

Out-of-Merit Change (\$000's)

Merit-Order Change (\$000's)

Out-of-Merit Change (\$000's)

Observations (Hour by Unit)

Number of Generating Units

Number of Plants

Total Capacity (MW)

$\begin{array}{ccc}28.6 & 7.9 & 26.5 \\ (0.6) & (0.4) & (0.5) \\ & & \\ 7.1 & 0.5 & -3.0 \\ (2.9) & (1.7) & (2.5)\end{array}$

Panel B: Weekday Summer Afternoons

$\begin{array}{ccc}41.6 & 7.5 & 27.4 \\ (1.6) & (0.5) & (1.4) \\ & & \\ 8.8 & 1.4 & -9.1 \\ (5.1) & (1.6) & (4.2)\end{array}$

Panel C: High Demand Hours

$\begin{array}{ccc}49.7 & 5.7 & 27.8 \\ (1.9) & (0.8) & (1.4) \\ & & \\ 16.3 & -0.5 & -14.5 \\ (4.8) & (1.7) & (4.8) \\ & & \\ 2,285,140 & 267,410 & 1,920,490 \\ 94 & 11 & 79 \\ 42 & 5 & 43 \\ 15,922 & 2,887 & 11,776\end{array}$

Note: This table reports estimates of the cost of meeting the lost generation from SONGS during the first twelve months following the closure. The format of the table and underlying data are identical to Table 3 , but we have used our measures of marginal cost for each generating unit to calculate the change in total generation cost. As we explain in the text, this includes changes in fuel expenditures and other marginal costs, but not capital costs or fixed O\&M. Standard errors (in parentheses) are clustered by sample month. 
Table 5: The Total Impact of the SONGS Closure

\begin{tabular}{c}
\hline \hline $\begin{array}{c}\text { Total Impact during the Twelve } \\
\text { Months following the Closure } \\
\text { (Millions of Dollars) }\end{array}$ \\
\hline
\end{tabular}

Merit-Order Net Increase in Generation Costs

Out-of-Merit Net Increase in Generation Costs

Value of Increased Carbon Dioxide Emissions

316

$(5.8)$

Note: This table reports our estimates of the total economic and environmental impact of the SONGS. The "merit-order net increase" subtracts annual generation costs at SONGS from the merit-order changes to thermal generation costs. The "out-of-merit" increase is the effect of insufficient transmission capacity. As we explain in the text, these generation costs includes changes in fuel expenditures and other marginal costs, but not capital costs or fixed O\&M. For comparison, annual fixed O\&M at nuclear plants is around $\$ 340$ million per year. Carbon is valued at $\$ 35 /$ ton, as described in the text. All dollar amounts in year 2013 dollars. Standard errors (in parentheses) are clustered by sample month. 


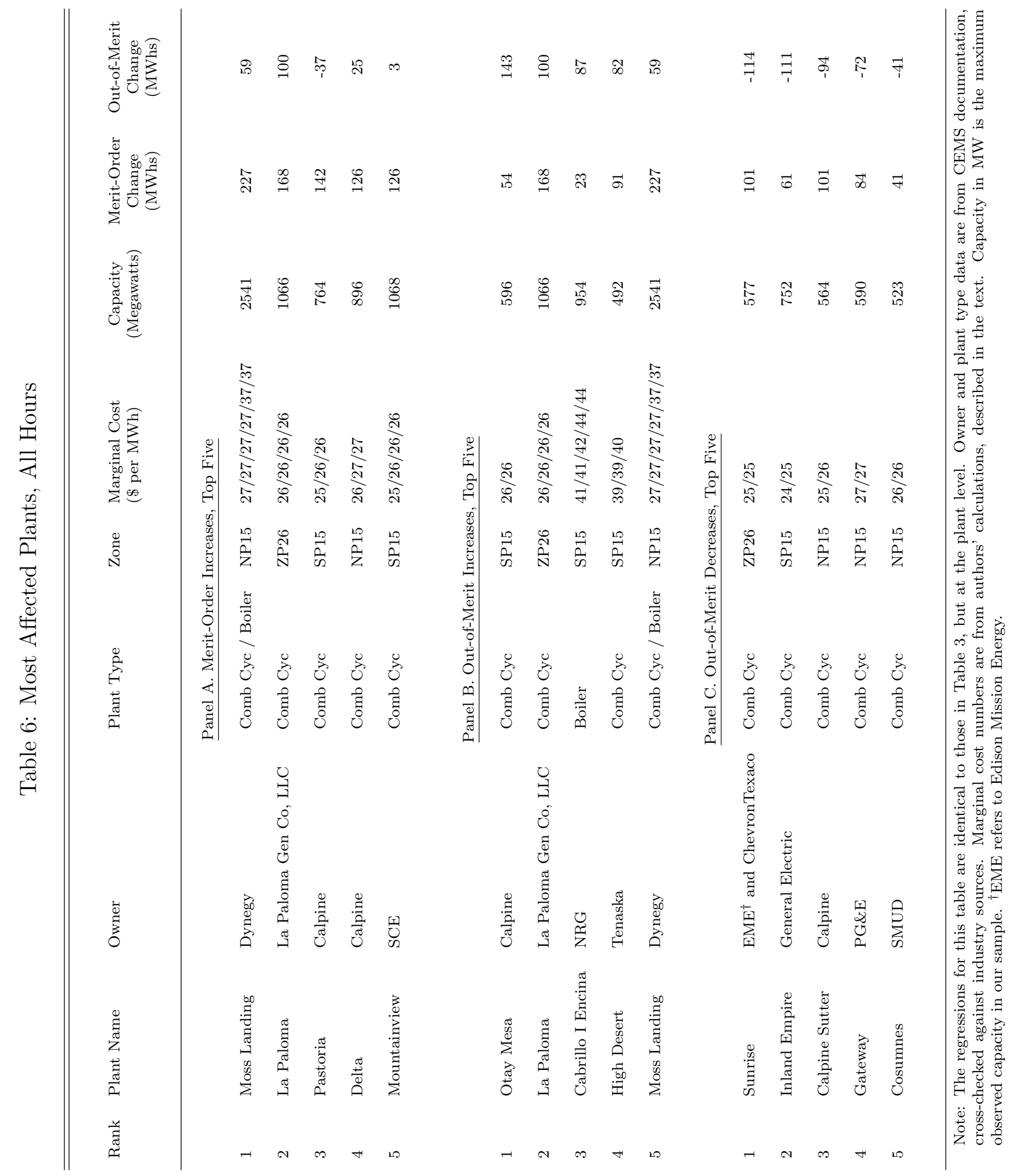




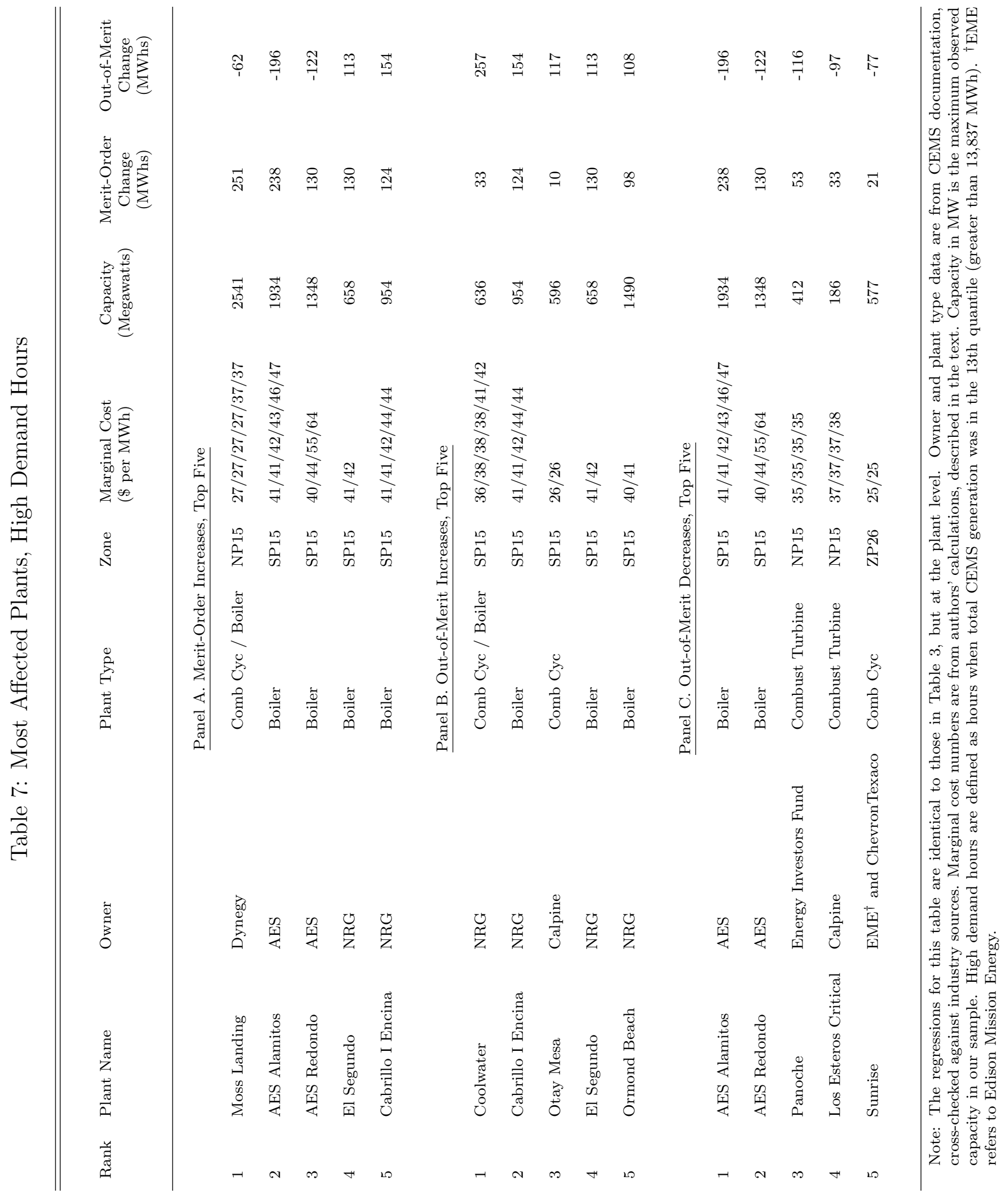




\section{Table 8: Separating Alamitos and Redondo}

\begin{tabular}{|c|c|c|c|c|}
\hline & \multicolumn{4}{|c|}{ Average Hourly Change, By Region } \\
\hline & AES & $\begin{array}{c}\text { Southern } \\
\text { California, } \\
\text { Excluding } \\
\text { AES }\end{array}$ & $\begin{array}{c}\text { Central } \\
\text { California }\end{array}$ & $\begin{array}{l}\text { Northern } \\
\text { California }\end{array}$ \\
\hline & (1) & $(2)$ & $(3)$ & $(4)$ \\
\hline & \multicolumn{4}{|c|}{ Panel A: All Hours } \\
\hline Merit-Order Change (MWh) & $\begin{array}{l}110 \\
(15)\end{array}$ & $\begin{array}{l}781 \\
(15)\end{array}$ & $\begin{array}{l}300 \\
(15)\end{array}$ & $\begin{array}{l}944 \\
(18)\end{array}$ \\
\hline \multirow[t]{2}{*}{ Out-of-Merit Change (MWh) } & $\begin{array}{l}-32 \\
(60)\end{array}$ & $\begin{array}{l}182 \\
(53)\end{array}$ & $\begin{array}{c}20 \\
(66)\end{array}$ & $\begin{array}{l}-140 \\
(49)\end{array}$ \\
\hline & \multicolumn{4}{|c|}{ Panel B: Weekday Summer Afternoons } \\
\hline Merit-Order Change (MWh) & $\begin{array}{l}339 \\
(31)\end{array}$ & $\begin{array}{l}729 \\
(27)\end{array}$ & $\begin{array}{l}259 \\
(17)\end{array}$ & $\begin{array}{l}822 \\
(39)\end{array}$ \\
\hline \multirow[t]{2}{*}{ Out-of-Merit Change (MWh) } & $\begin{array}{r}-311 \\
(94)\end{array}$ & $\begin{array}{c}548 \\
(105)\end{array}$ & $\begin{array}{c}76 \\
(61)\end{array}$ & $\begin{array}{l}-260 \\
(119)\end{array}$ \\
\hline & \multicolumn{4}{|c|}{ Panel C: High Demand Hours } \\
\hline Merit-Order Change (MWh) & $\begin{array}{l}455 \\
(42)\end{array}$ & $\begin{array}{l}752 \\
(34)\end{array}$ & $\begin{array}{l}174 \\
(30)\end{array}$ & $\begin{array}{l}753 \\
(35)\end{array}$ \\
\hline Out-of-Merit Change (MWh) & $\begin{array}{l}-310 \\
(127)\end{array}$ & $\begin{array}{c}742 \\
(111)\end{array}$ & $\begin{array}{c}4 \\
(57)\end{array}$ & $\begin{array}{l}-381 \\
(129)\end{array}$ \\
\hline Observations (Hour by Unit) & 340,340 & $1,944,800$ & 267,410 & $1,920,490$ \\
\hline Number of Generating Units & 14 & 80 & 11 & 79 \\
\hline Number of Plants & 3 & 39 & 5 & 43 \\
\hline Total Capacity (MW) & 4,167 & 11,755 & 2,887 & 11,776 \\
\hline
\end{tabular}

